\title{
Article
}

\section{Fabrication and Characterization of Bio-Epoxy Eggshell Composites}

\author{
Stephen Owuamanam ${ }^{1}$, Majid Soleimani ${ }^{2}$ and Duncan E. Cree ${ }^{1, * \mathbb{D}}$ \\ 1 Department of Mechanical Engineering, University of Saskatchewan, Saskatoon, SK S7N 5A9, Canada; \\ stephen.owuamanam@usask.ca \\ 2 Department of Chemical and Biological Engineering, University of Saskatchewan, \\ Saskatoon, SK S7N 5A9, Canada; mas233@mail.usask.ca \\ * Correspondence: duncan.cree@usask.ca; Tel.: +1-306-966-3244
}

check for updates

Citation: Owuamanam, S.; Soleimani, M.; Cree, D.E. Fabrication and Characterization of Bio-Epoxy Eggshell Composites. Appl. Mech. 2021, 2, 694-713. https://doi.org/ 10.3390/applmech2040040

Received: 11 August 2021

Accepted: 23 September 2021

Published: 29 September 2021

Publisher's Note: MDPI stays neutral with regard to jurisdictional claims in published maps and institutional affiliations.

\begin{abstract}
In this study, an innovative composite was fabricated in which the matrix is partially derived from natural sources and the filler from undervalued eggshell waste material. The effect of coating eggshells and mineral limestone with $2 \mathrm{wt} . \%$ stearic acid on the mechanical properties of a bio-epoxy matrix was investigated. Eggshells and limestone (untreated and stearic acid-treated) fillers were added to the bio-epoxy matrix in quantities of 5, 10, and $20 \mathrm{wt} . \%$ loadings using a solution mixing technique. The $\mathrm{CaCO}_{3}$ content in eggshells was confirmed to be $88 \mathrm{wt} . \%$, and the crystalline phase was found to be calcite. The stearic acid coating did not show any decrease in crystallinity of the fillers. Scanning electron microscopy (SEM) displayed changes in the fractured surfaces, which infers the fillers altered the bio-epoxy polymer. The mechanical property results showed enhancements in the composite tensile modulus and flexural modulus compared to the pure bio-epoxy, as expected. In contrast, despite the improvement in the tensile and flexural strengths of the stearic acid-treated fillers, the composite strength values were not higher than those of the unfilled bio-epoxy matrix. The energy absorbed by all composites in Charpy impact tests fell below that of the pure bio-epoxy and decreased with an increase in filler content for both untreated and stearic acid-treated fillers tested at 23 and $-40{ }^{\circ} \mathrm{C}$. Statistical analysis of the results was conducted using Statistical Analysis Software (SAS) with ranking based on Tukey's method. The study identified that the addition of 5, 10 , and $20 \mathrm{wt} . \%$ in a bio-epoxy matrix may be acceptable provided the end product requires lower tensile and flexural load requirements than those of the pure bio-epoxy. However, filler loadings below $5 \mathrm{wt}$ \% would be a better choice.
\end{abstract}

Keywords: eggshell waste; calcium carbonate; bio-epoxy; composite; mechanical testing

\section{Introduction}

In recent years, there has been an uptake in the use of polymer composites for various applications due to their light weight, high specific stiffness, and moderate strength properties. During and after World War II (1940s) there was an increase in the production and development of synthetic polymers and plastics produced from petroleum resources [1]. Synthetic epoxy is frequently utilized in diverse applications due to its simple processing methods, good elevated temperature properties, and exceptional strength. Generally, epoxy polymers have a higher purchase cost than other thermoset polymers; however, in the aerospace industry, more than two-thirds of polymers utilized are based on epoxy [2]. As a green alternative, bio-based epoxy resins are synthesized from modified plant oils, sugars, polyphenols, and terpenes [3], where resins contain 31-55\% bio-contents. Therefore, bio-based epoxy resins could serve as substitutes to petroleum-based epoxy resins.

Because the cost of polymers can be relatively high, it has been customary to add lower cost fillers to reduce the overall cost of the raw composite materials while in some cases improving their properties. Limestone, a mineral with a high calcium carbonate content $\left(\mathrm{CaCO}_{3}\right)$ is a common filler used to replace part of the more expensive polymer matrix and can also improve the stiffness of the components. Another source of calcium carbonate 
not widely discussed is waste chicken eggshells. Recent studies revealed eggshells contain 94-96 wt.\% $\mathrm{CaCO}_{3}$ in the form of calcite, 3-4 wt.\% organic matter, and negligible traces of magnesium, phosphorus, and other elements [4-6].

Egg breaking plants (sometimes referred to as "breaker plants") produce enormous quantities of eggshell waste as a by-product and are largely discarded in landfills. Eggshells are compostable because they can decompose and add nutrients to the soil. However, issues arise when the quantity of discarded eggshells is very large, i.e., when measured in tons. During their decomposition, ammonia $\left(\mathrm{NH}_{3}\right)$ and hydrogen sulfide $\left(\mathrm{H}_{2} \mathrm{~S}\right)$ are emitted, which can be unfavorable for the environment, and the produced salmonella bacteria can be harmful to humans. More importantly, the cost of landfilling waste eggshell is significant. For instance, breaker plants in Europe and in the United States of America spend approximately USD 100,000 annually to dispose of eggshells in landfills [7]. One means to redirect waste eggshells is to use them in polymers as fillers. A recent review article estimated the amount of $\mathrm{CaCO}_{3}$ that could be recovered from waste eggshells in the top ten annual egg producing countries [8]. For example, China's annual production of eggs in 2017 was 536,818,007,000. Of this amount, 30\% of eggs are generally sent to breaker plants, which amounts to $161,045,402,000$ eggs. Based on the dry empty shell weighing $6.6 \mathrm{~g}$, about 1,062,899,654 $\mathrm{kg}$ of $\mathrm{CaCO}_{3}$ could be recovered. In practical terms, $\sim 35,429,988$ bags of $\mathrm{CaCO}_{3}$ each weighing $30 \mathrm{~kg}$ can be recovered from eggshell waste annually for use in various applications. Repurposing waste eggshells can be seen as a cost-effective alternative to paying disposal tipping fees at the landfill.

When $\mathrm{CaCO}_{3}$ filler particulates are incorporated into polymers, agglomeration has been recognized as a disadvantage in several studies [9-11]. The cluster of fine particles was reported to cause micro-cracks, which are alleged to lead to brittle fractures in polymer composites [12]. In an effort to enhance dispersion of fillers and improve bonding at the interface between matrix and filler, the most widely used surface coating on $\mathrm{CaCO}_{3}$ powder has generally been stearic acid, an inexpensive fatty acid. The quantity of stearic acid required to effectively coat $\mathrm{CaCO}_{3}$ powders has been investigated $[9,13]$. In one study, $0.5-4$ wt.\% of stearic acid was coated on the surface of calcite fillers. The amount necessary to coat the surface of the calcite particles with a single layer of stearic acid was suggested to be between 1.5 and 2 wt.\% [13]. In a recent study, eggshell powder was modified with $1-3 \mathrm{wt} . \%$ stearic acid and added to a synthetic epoxy resin. The tensile elongation property showed an improvement when $2.5 \mathrm{wt}$.\% stearic acid was used compared to the pure epoxy, which the authors attributed to hydrogen bonding between stearic acid coated particles and the matrix [9]. The literature suggests that a lower amount of stearic acid is more effective.

This work reports the fabrication of bio-epoxy composites containing untreated and stearic acid-treated $\mathrm{CaCO}_{3}$ powders, derived from waste eggshells and conventional mineral limestone. The tensile strength/modulus, flexural strength/modulus, and Charpy impact energy of bio-epoxy composites containing different amounts of $\mathrm{CaCO}_{3}$ fillers were compared against those of bio-epoxy. Inductively coupled plasma mass spectrometry (ICP-MS) was used to determine the $\mathrm{CaCO}_{3}$ content in the prepared eggshell filler. X-ray diffraction (XRD) identified the crystalline phase of both eggshell and limestone powders. Scanning electron microscopy (SEM) was used to view the $\mathrm{CaCO}_{3}$ filler morphologies and fractured surfaces of the composites. Differential scanning calorimetry (DSC) was implemented to assess whether the fillers had an effect on the glass transition temperature $\left(\mathrm{T}_{\mathrm{g}}\right)$ of the composite materials.

\section{Materials and Methods}

\subsection{Materials}

The matrix was a green bio-epoxy polymer (Super Sap CPM resin and CPL hardener) obtained from Entropy Resins Inc., San Antonio, TX, USA, and containing a bio-based content of $31 \%$. The mix ratio of resin: hardener (by weight) was 100:40. The fillers were white eggshell obtained from eggshell waste and mineral limestone was purchased from Imasco Minerals Inc., Surrey, BC, Canada. Silicone molds for specimen fabrication were 
made from Mold Max ${ }^{\circledR}$ 10T (Smooth-On Inc., Macungie, PA, USA). Stearic acid in the form of flakes was acquired from Acros Organics, 97\% purity (Fisher Scientific., Ottawa, ON, Canada).

\subsection{Eggshell Powder Preparation}

The as-received waste eggshells were prepared by coarse crushing, rinsing with water, and drying at $105^{\circ} \mathrm{C}$ for $24 \mathrm{~h}$ to eliminate water, odor, and contaminants from the organic membranes and egg remnants [4]. The coarse ground eggshells were further ball milled for $6 \mathrm{~h}$ into fine powders using a small-scale milling apparatus to further reduce the particle size. Distilled water was added to the fine eggshell powders and manually agitated, and a precipitation process was used to remove additional membranes followed by a drying step. After a vigorous agitation, sufficient time was given to allow the denser eggshell particle suspension to settle to the bottom of the pail, while the lighter eggshell membranes floated to the top. By slowly tipping the container, the membranes flowed out of the pail. The eggshell and limestone powders were each sieved to $32 \mu \mathrm{m}$ (No. 450) mesh using a vibrating sieve shaker machine (Ro-tap).

The eggshell and limestone fillers were treated with 2 wt.\% stearic acid as proposed in a previous study [13]. Individually, $100 \mathrm{~g}$ of eggshell or limestone powder was added to a beaker containing $100 \mathrm{~mL}$ of ethanol and $300 \mathrm{~mL}$ of distilled water at a weight/volume/volume ratio (1:1:3) (powder: ethanol: water). The solution was stirred using a magnetic stirrer for $2 \mathrm{~h}$ at room temperature $\left(23^{\circ} \mathrm{C}\right)$ in order to completely wet the particles. In a separate glass beaker, to obtain a $2 \mathrm{wt} \%$ stearic acid in the final solution, $9.156 \mathrm{~g}$ of stearic acid chips was dissolved in $100 \mathrm{~mL}(78.8 \mathrm{~g})$ of ethanol. The powder/ethanol/distilled water mixture was stirred and heated until it reached $80{ }^{\circ} \mathrm{C}$ and the $2 \mathrm{wt}$ \% stearic acid solution was added dropwise over a $30 \mathrm{~min}$ period. The mixture was stirred for an additional $2.5 \mathrm{~h}$ to ensure homogenization and finally filtered using a filter paper of particle retention 5-10 $\mu \mathrm{m}$. The stearic acid coated powder was subsequently dried at $105{ }^{\circ} \mathrm{C}$ for $24 \mathrm{~h}$ and agglomerated particles were separated using a mortar and pestle.

\subsection{Particle Size Analysis}

Particle size analysis was undertaken with a Malvern Mastersizer 2000 S (long bench) laser diffraction particle size analyzer using a dry dispersion method. The apparatus uses two laser light sources consisting of a blue light (wavelength $466 \mathrm{~nm}$ ) and a red light (wavelength $633 \mathrm{~nm}$ ) to obtain the particle size distribution. The process was repeated three times to ensure reproducibility and the average results are reported.

\subsection{Bio-Epoxy/Calcium Carbonate Composite Preparation}

Four fillers (untreated eggshell, untreated limestone, eggshell treated with stearic acid, and limestone treated with stearic acid) were added in separate batches to the bio-epoxy matrix using a solution mixing method. Formulations consisted of adding three different weight fractions of the fillers as replacements of the matrix in loadings of 5, 10, and $20 \mathrm{wt}$.\%, and are listed in Table 1. Prior to dispersing the fillers in the matrix, the eggshell and limestone powders were degassed (shell lab Model SVAC1E) under vacuum $>28$ inHg for $30 \mathrm{~min}$ at $23^{\circ} \mathrm{C}$ to eliminate air in the pores of the particulates. The required amount of bioepoxy resin was first poured into a $2000 \mathrm{~mL}$ polypropylene beaker followed by the addition of the appropriate amount of filler. The mixture was dispersed using a magnetic stirrer rotating at $700 \mathrm{rpm}$ for $1 \mathrm{~h}$. To improve dispersion of the particles within the bio-epoxy, an ultrasonic homogenizer (Model FS-900N, MXBAOHENG, Shanghai Shengxi Co. Ltd., Shanghai, China) was used to further disperse the fillers for $5 \mathrm{~min}$. In Bittmann et al. [14], a duration of $5 \mathrm{~min}$. was suggested for dispersion of fillers using an ultrasonic homogenizer to avoid degradation of the epoxy mechanical properties. Excessive sonication may increase the temperature and viscosity, which could prevent effective dispersion of fillers due to the start of resin curing without addition of the hardener [15]. The liquid resin/filler mixtures were degassed under vacuum (28 in $\mathrm{Hg}$ ) for $30 \mathrm{~min}$ to evacuate air bubbles generated from 
mixing. Subsequently, the necessary amount of hardener was added and stirred manually for $3 \mathrm{~min}$ followed by degassing for $15 \mathrm{~min}$. The bio-epoxy formulations were slowly poured into silicone rubber molds having specific geometries for specimen testing. The Mold Max 10T was mixed at a weight ratio of 100:10 (silicone rubber: hardener) and cured for $24 \mathrm{~h}$ at room temperature and demolded. The silicone rubber molds were subjected to a post-cure at $65^{\circ} \mathrm{C}$ for $4 \mathrm{~h}$ as instructed by the supplier's data sheet to improve the tearing properties. The composites were cured for $24 \mathrm{~h}$ at room temperature and post-cured at $82{ }^{\circ} \mathrm{C}$ for $40 \mathrm{~min}[16]$.

Table 1. Formulations of filler in the bio-epoxy composites.

\begin{tabular}{ccc}
\hline Filler (wt.\%) & Resin (wt.\%) & Hardener (wt.\%) \\
\hline 0 & 71.43 & 28.57 \\
5 & 67.86 & 27.14 \\
10 & 64.29 & 25.71 \\
20 & 57.14 & 22.86 \\
\hline
\end{tabular}

\subsection{Measurements and Characterization}

ICP-MS was used to determine the calcite or $\mathrm{CaCO}_{3}$ content in the prepared eggshell filler. The powdered samples were digested in $65 \mathrm{wt} . \%$ concentrated nitric acid at $200{ }^{\circ} \mathrm{C}$ in a closed vessel employing a microwave digestion system (Model CEM Corporation Mars 6, Matthews, NC, USA) using 1800 watts of microwave energy at a frequency of $2450 \mathrm{MHz}$. An ICP-MS (Agilent 7700x ICP-MS, Tokyo, Japan) was used to measure elemental composition. The tests were performed in triplicate and averaged. The obtained $\mathrm{CaCO}_{3}$ composition of eggshells was compared with mineral limestone as reported in the supplier's technical data sheet. XRD was used to identify the crystalline phase of both eggshell and limestone powders using an X-ray diffractometer (Ultima IV, Rigaku Americas Corporation, Woodlands, TX, USA) with $\mathrm{Cu} \mathrm{K} \alpha$ radiation operating at $40 \mathrm{kV}$ and $44 \mathrm{~mA}$, at a scanning rate of $4.0^{\circ} / \mathrm{min}$ and a diffraction angle $(2 \theta)$ between $20^{\circ}$ and $50^{\circ}$. Filler powder morphology, and tensile and flexure fractured surfaces, were observed by a scanning electron microscope (SEM) (JEOL JSM-6010 LV) (Tokyo, Japan) operated at 7-15 kV. The samples were sputter gold coated to make them conductive before being examined. Tensile and three-point flexural tests were conducted using an Instron universal testing machine (Model No. 3366, Instron Corp., Norwood, MA, USA) equipped with a $5 \mathrm{kN}$ load cell. Tensile strength was evaluated at a cross-head speed of $10 \mathrm{~mm} / \mathrm{min}$ according to ASTM D638-14 [17]. The dog-bone sample dimensions were $165 \times 13 \times 3.2 \mathrm{~mm}(1 \times \mathrm{w} \times \mathrm{t})$. Flexural sample dimensions were $200 \times 20 \times 10 \mathrm{~mm}(1 \times \mathrm{w} \times \mathrm{t})$ with a span to depth ratio of 16:1 as recommended by the ASTM D790-17 standard [18]. The cross-head speed was $4 \mathrm{~mm} / \mathrm{min}$. Charpy impact tests were performed with an Instron Model $450 \mathrm{MPX}$ (Instron, Norwood, MA, USA) series impact tester. In this test, ASTM standard D6110-18 [19] was used as a guide to compare the impact toughness of the composites at various filler loadings with respect to the unfilled bio-epoxy matrix. The tests were performed on un-notched, non-standard specimens of dimensions $55 \times 13 \times 3.2 \mathrm{~mm}(1 \times \mathrm{w} \times \mathrm{t})$. It was reported that un-notched samples were better for determining the presence of agglomerates from powder fillers added to composite materials compared to notched test specimens that are insensitive to agglomerates [20]. To determine if temperature had an influence on the impact behavior of the composites, the samples were conditioned at $23{ }^{\circ} \mathrm{C}$ and $-40{ }^{\circ} \mathrm{C}$ for $4 \mathrm{~h}$ in a Tenney Environmental Chamber (Tenney Engineering Inc., Parsippany, NJ, USA) prior to testing. Tensile, flexural, and Charpy impact tests utilized an average of five specimens for each composite formulation. The $\mathrm{T}_{\mathrm{g}}$ of the composite materials was investigated using a DSC (Model 2910 V4.4E, TA Instruments, New Castle, DE, USA) according to the ASTM E1356-08 (2014) [21] standard. Samples were prepared in a powder form of approximately 7-10 $\mathrm{mg}$ and placed in an aluminum pan and heated from 22 to $80{ }^{\circ} \mathrm{C}$ at a heating rate of $10{ }^{\circ} \mathrm{C} \mathrm{min}^{-1}$ under nitrogen atmosphere. Statistical analysis of 
the data was conducted using Statistical Analysis Software, SAS 9.4 (SAS Institute, Cary, NC, USA) with ranking based on Tukey's method.

\section{Results and Discussion}

\subsection{Chemical Composition Analysis (Powders)}

ICP-MS elemental analysis of eggshells revealed a comparatively high $\mathrm{CaCO}_{3}$ content of $88 \mathrm{wt} . \% \pm 0.71$ with traces of magnesium $(0.27 \%)$ and phosphorus $(0.13 \%)$, compared to $99.9 \mathrm{wt} . \% \mathrm{CaCO}_{3}$ content for limestone as reported in the supplier's data sheet. The variations in $\mathrm{CaCO}_{3}$ chemical composition contents from the literature may be due to the different sample preparation for different chemical analysis techniques. In addition, in an earlier study on the same waste eggshell batch, inductively coupled plasma-optical emission (ICP-OES) was performed and the results showed elements of chloride $(0.058 \%)$, sulphate $(0.034 \%)$, and sulfur $(0.067 \%)$ [4]. The minor difference in composition was anticipated because the eggshells contain organic matter which is absent in limestone. Although significant attempts were made to remove organic membranes using an agitation technique, they were still present in the samples. A recent article showed eggshells have an inner and outer membrane where the inner membrane is easier to remove than the outer membrane. The study suggested heating eggshells to $450{ }^{\circ} \mathrm{C}$ would allow the organic membranes to be removed without changing the composition of $\mathrm{CaCO}_{3}$; however, there is an apparent color change to gray with carbon remnants [22]. It is well known that calcination of $\mathrm{CaCO}_{3}$ above $800{ }^{\circ} \mathrm{C}$ causes conversion into calcium oxide $(\mathrm{CaO})$. A slightly higher heat treatment below the formation of $\mathrm{CaO}$ may remove the carbon. For composite materials, depending on the color or type of polymer matrix, color change may not have an impact on the end product. In another study, a 10\% bleach treatment soaked for $48 \mathrm{~h}$ or a $50 \%$ bleach treatment soaked for $10 \mathrm{~min}$ was able to remove the organic membrane to produce pure calcite [23]. The aim of this current work was to avoid the use of chemicals and/or additional processing.

\subsection{X-ray Diffraction Analysis (Powders)}

XRD patterns were obtained for untreated eggshells, untreated limestone, eggshell treated with stearic acid, and limestone treated with stearic acid, in addition to stearic acid particulates for comparison, and are presented in Figure 1. The diffraction peaks of eggshell and limestone suggested the crystalline phase to be $\mathrm{CaCO}_{3}$ in the form of calcite. As previously reported, the most thermodynamically stable polymorph of $\mathrm{CaCO}_{3}$ is calcite [24]. The major intensity peak was found at a $2 \theta$ angle of $29.4^{\circ}$, while minor peaks occurred at $23.2^{\circ}, 31.5^{\circ}, 36.1^{\circ}, 39.6^{\circ}, 43.3^{\circ}, 47.7^{\circ}$, and $48.7^{\circ}$ for both eggshell and limestone, as also reported in the literature [25]. Stearic acid presented two characteristic peaks at $21.5^{\circ}$ and $24.1^{\circ}$. The diffracted peaks of stearic acid particulates did not show on the eggshell, limestone, or both stearic acid-treated fillers. This suggests that the stearic acid content ( $2 \mathrm{wt} . \%)$ used to treat the fillers was too small to be identified by the XRD detector. In a previous study, XRD diffraction peaks of $2.5 \mathrm{wt} . \%$ stearic acid were not apparent on stearic acid coated calcium carbonate particles. However, the presence of stearic acid is expected to reduce the diffraction peak intensities of calcium carbonate without changing the crystalline structure [9]. Stearic acid has a low crystallinity and tends to decrease the diffraction peak intensities.

\subsection{Scanning Electron Microscopy Analysis (Powders)}

The micrographs of eggshell, limestone, eggshell treated with stearic acid, and limestone treated with stearic acid fillers are presented in Figure 2a-d. Both untreated and treated fillers have similar structures showing coarse and irregular morphologies, possibly due to both filler types being reduced by a crushing/grinding process. In general, the eggshell (Figure 2a) and limestone (Figure 2c) tend to exhibit a rhombohedral-like morphology, suggesting the existence of calcite crystals [5]. The eggshell particles treated with 
stearic acid (Figure $2 \mathrm{~b}$ ) and limestone particles treated with stearic acid (Figure 2d) had fewer rough/sharp edges, possibly due to the applied coatings.

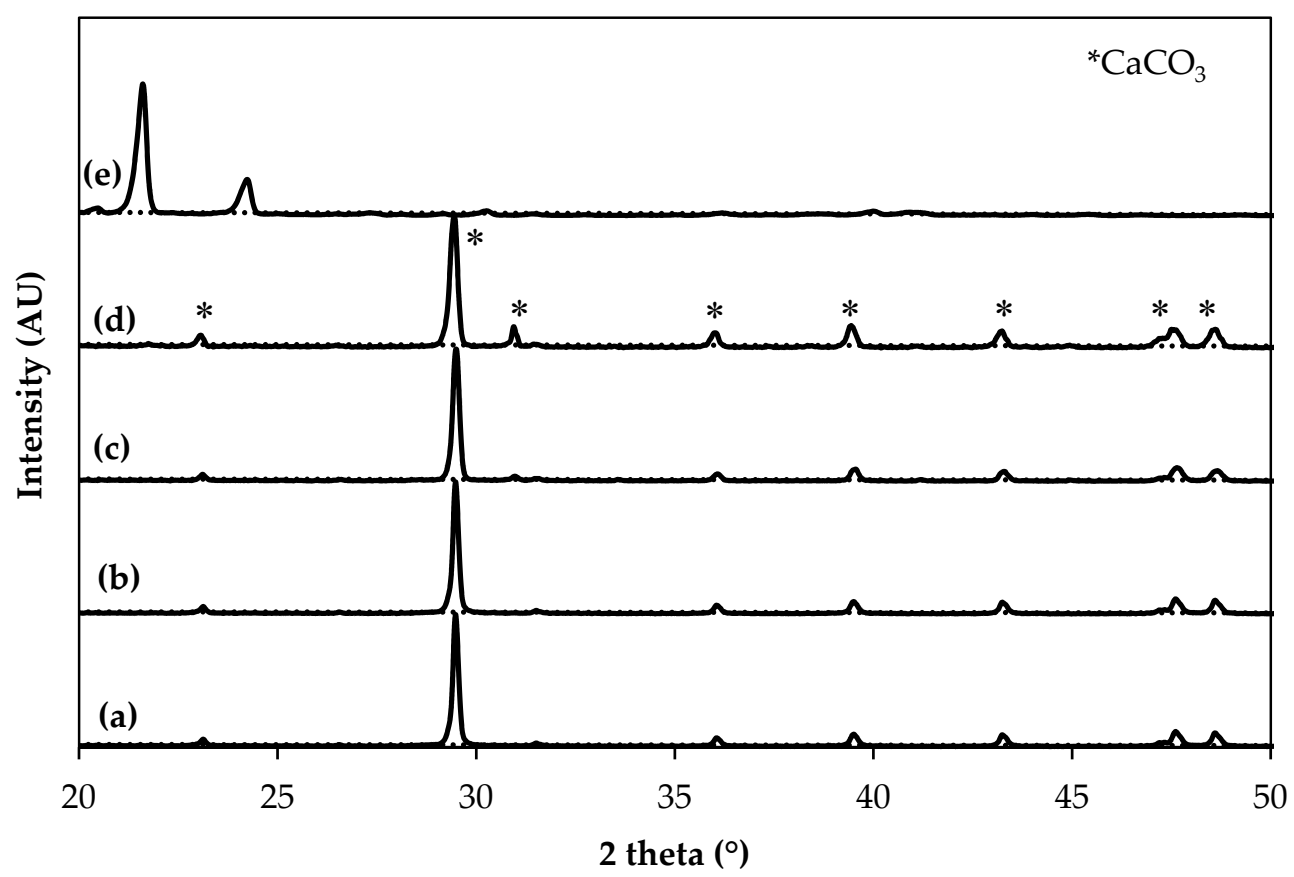

Figure 1. X-ray diffraction (XRD) patterns of (a) eggshells, (b) eggshells treated with stearic acid, (c) limestone, (d) limestone treated with stearic acid, and (e) stearic acid particulates.
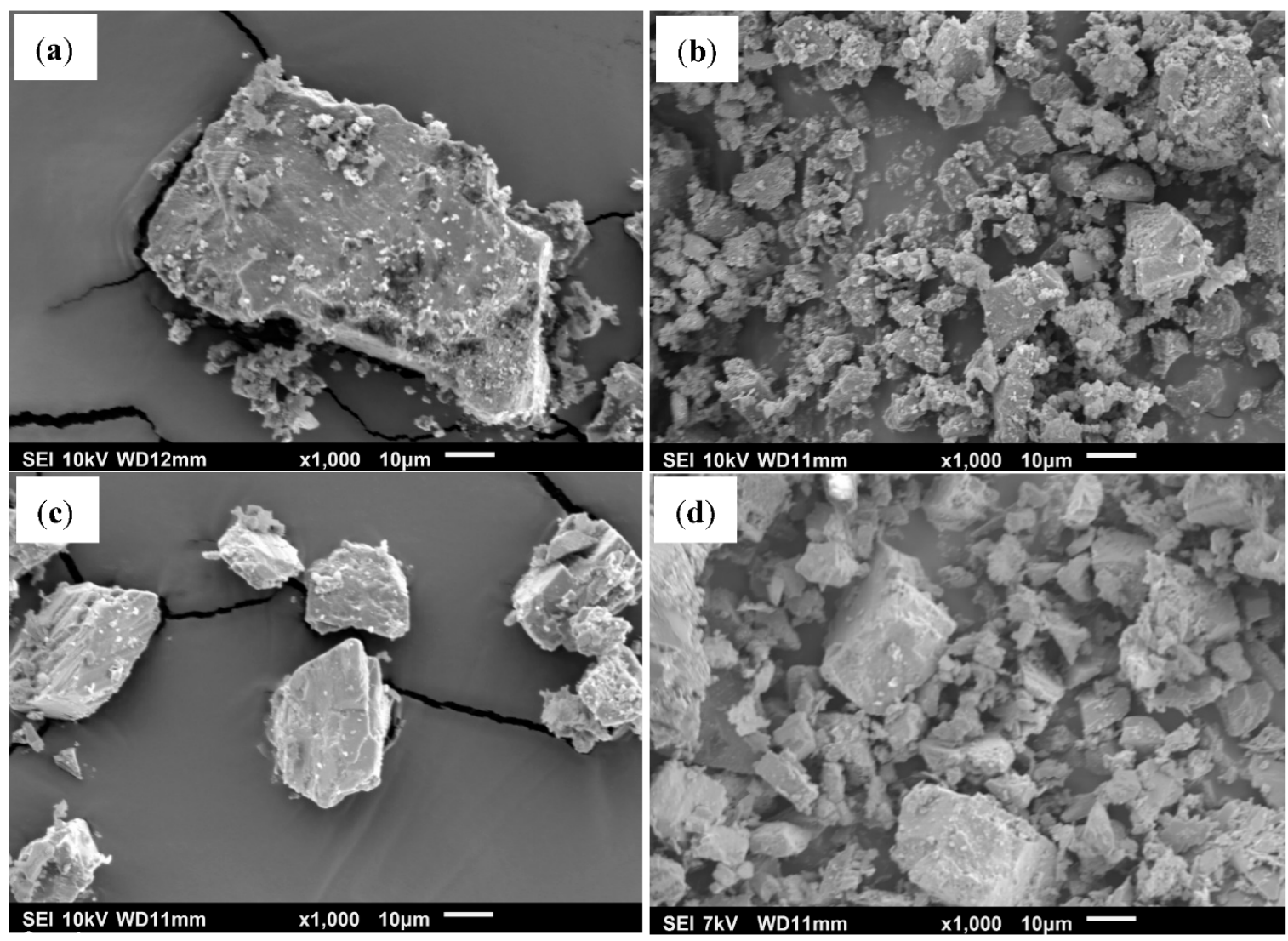

Figure 2. SEM micrographs showing particle morphologies of (a) eggshell, (b) eggshell/stearic acid treated, (c) limestone, and (d) limestone/stearic acid treated. 


\subsection{Particle Size Analysis}

The particle size distribution curve (PSDC) of the prepared eggshell (ES), eggshell treated with stearic acid (ES/SA), limestone (LS), and limestone treated with stearic acid (LS/SA) are shown in Figure 3. The average particle size based on volume distribution was determined to be $21.2 \pm 2.0 \mu \mathrm{m}, 11.5 \pm 1.0 \mu \mathrm{m}, 25.1 \pm 2.2 \mu \mathrm{m}$ and $12.8 \pm 2.2 \mu \mathrm{m}$, respectively. Slight differences in untreated eggshell and limestone powders may be attributed to the particle reduction method. As shown in Figure 3a,b, the eggshell and limestone fillers had a broader particle size distribution range compared to the stearic acid treated fillers, which had a narrower range. Comparable results in particle size distribution were obtained for $1 \mathrm{wt} . \%$ stearic acid-coated $\mathrm{CaCO}_{3}$ particles [26]. The differences were believed to be due to larger agglomerated particles being easily separated into smaller lumps due to the stearic acid coating.
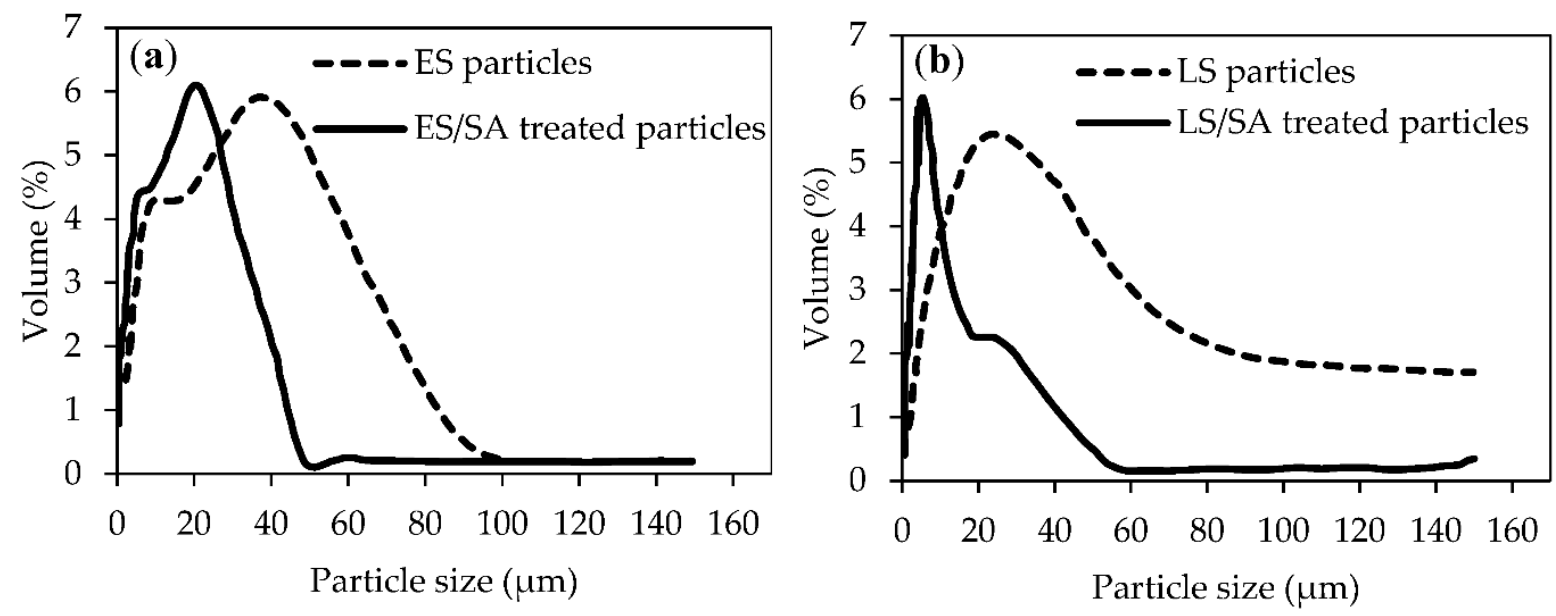

Figure 3. Particle size volume distribution curves for (a) eggshell (ES) and eggshell/stearic acid treated (ES/SA) and (b) limestone (LS) and limestone/stearic acid treated (LS/SA).

\subsection{Scanning Electron Microscopy Analysis (Fractured Surfaces)}

Figure 4 shows the tensile fractured surfaces of the unfilled bio-epoxy (Figure 4a), bio-epoxy containing $5 \mathrm{wt}$ \% \% untreated eggshells (Figure $4 \mathrm{~b}$ ), bio-epoxy containing $5 \mathrm{wt}$.\% eggshells treated with stearic acid (Figure 4c), bio-epoxy containing $20 \mathrm{wt} . \%$ untreated eggshells (Figure $4 \mathrm{~d}$ ), bio-epoxy containing $20 \mathrm{wt} . \%$ eggshells treated with stearic acid (Figure 4e), bio-epoxy containing $5 \mathrm{wt} . \%$ untreated limestone (Figure 4f), bio-epoxy containing $5 \mathrm{wt} . \%$ limestone treated with stearic acid (Figure $4 \mathrm{~g}$ ), bio-epoxy containing $20 \mathrm{wt} . \%$ untreated limestone (Figure $4 \mathrm{~h}$ ), and bio-epoxy containing $20 \mathrm{wt} . \%$ limestone treated with stearic acid (Figure $4 \mathrm{i}$ ). The loadings of 5 and $20 \mathrm{wt} . \%$ were selected to view morphologies of the composites containing minimum and maximum filler contents. A similar approach was followed where SEM fractured surfaces were reported for only 10 and $30 \mathrm{wt} . \%$ for a study that added $0,10,20,30$, and $40 \mathrm{wt} . \%$ eggshell fillers in a polypropylene matrix [10]. The fractured surface of the unfilled bio-epoxy resin had smooth and cleavage features indicative of a brittle fracture. It also showed fewer uninterrupted crack paths after initiation compared to the composites. Similar fractured surfaces were observed with untreated and stearic acid treated composites. The micrographs of the fractured surfaces for composites containing $5 \mathrm{wt} . \%$ fillers (Figure $4 \mathrm{~b}, \mathrm{c}, \mathrm{f}, \mathrm{g}$ ) showed a greater degree of roughness (white ridges), which may be due to more crack initiation and propagation sites as a result of filler additions. The degree of roughness further increased at $20 \mathrm{wt} . \%$ filler loadings (Figure $3 \mathrm{~h}, \mathrm{i}$ and Figure $4 \mathrm{~d}$,e). Overall, the differences in the tensile fractured surfaces suggest fillers played a role in changing the bio-polymer matrix. 


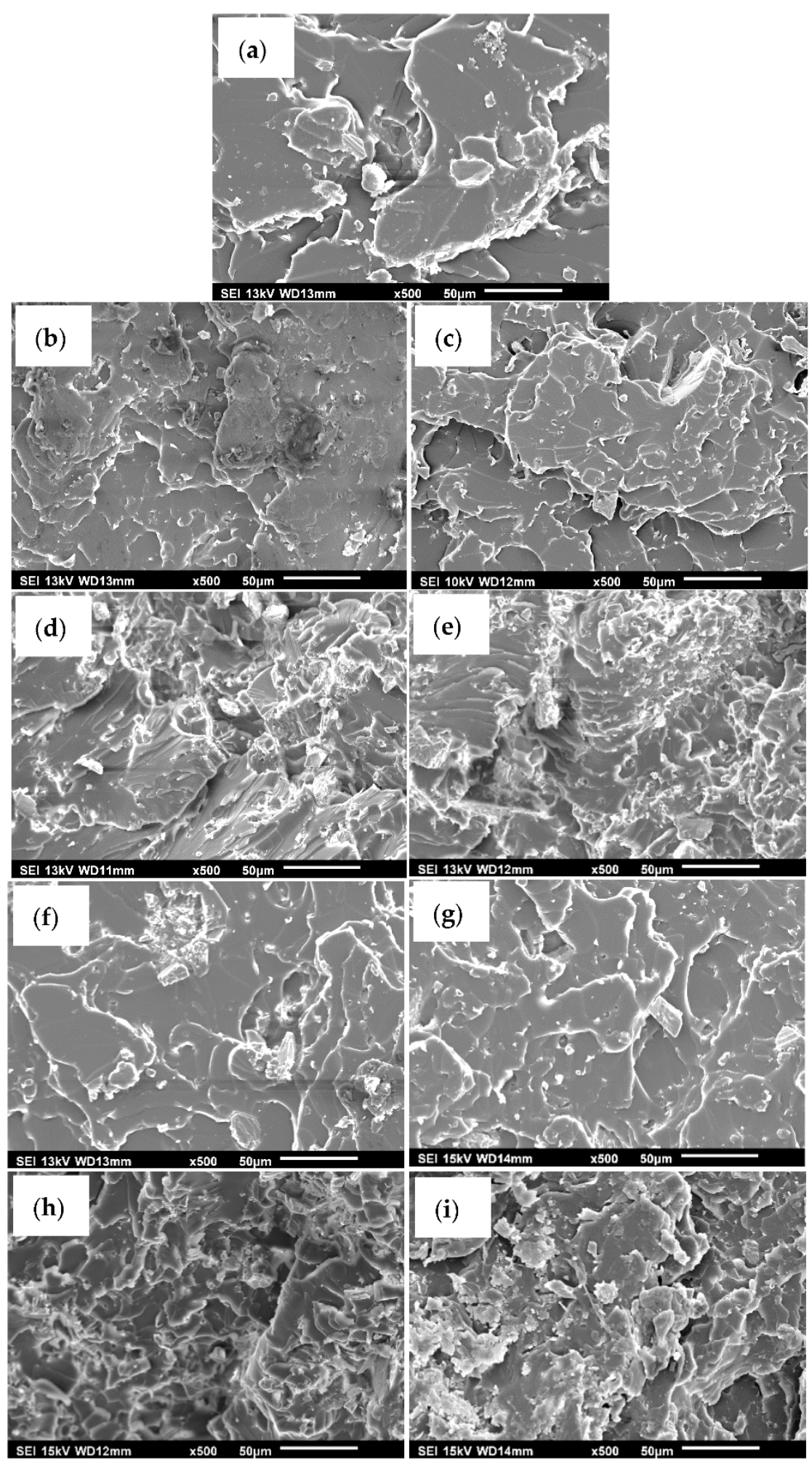

Figure 4. SEM micrographs of tensile fractured surfaces of (a) unfilled bio-epoxy, (b) 5 wt.\% ES, (c) 5 wt.\% ES/SA, (d) 20 wt.\% ES, (e) 20 wt.\% ES/SA, (f) 5 wt.\% LS, (g) 5 wt.\% LS/SA, (h) 20 wt.\% LS and (i) $20 \mathrm{wt} . \%$ LS/SA.

Figure 5 shows the flexural fractured surfaces of the unfilled bio-epoxy (Figure 5a), bio-epoxy filled with $5 \mathrm{wt} . \%$ untreated eggshells (Figure $5 b$ ), bio-epoxy filled with $5 \mathrm{wt} . \%$ eggshells treated with stearic acid (Figure 5c), bio-epoxy filled with $20 \mathrm{wt} . \%$ untreated eggshells (Figure $5 \mathrm{~d}$ ), bio-epoxy filled with $20 \mathrm{wt} . \%$ eggshells treated with stearic acid 
(Figure 5e), bio-epoxy filled with 5 wt.\% untreated limestone (Figure 5f), bio-epoxy filled with 5 wt.\% limestone treated with stearic acid (Figure $5 \mathrm{~g}$ ), bio-epoxy filled with $20 \mathrm{wt} \%$ untreated limestone (Figure 5h), and bio-epoxy filled with $20 \mathrm{wt} . \%$ limestone treated with stearic acid (Figure 5i). The fractured surface of the unfilled bio-epoxy resin presented a smooth, plate-like, and cleavage surface suggesting brittle failure. In a similar manner as the tensile fractured surfaces, the unfilled bio-epoxy presented fewer uninterrupted crack paths after initiation in comparison to the composites. Both untreated and stearic acid treated fillers showed slightly rougher fractured surfaces due to the addition of fillers compared to the unfilled bio-epoxy and further increased with $20 \mathrm{wt}$ \% filler loadings. Greater quantities of filler contents tend to encourage stress concentrations, which generate additional cracks and reduce mechanical strength properties.

\subsection{Tensile Properties}

The effect of untreated eggshell, untreated limestone, eggshell treated stearic acid, and limestone treated stearic acid filler loadings of 5, 10, and $20 \mathrm{wt} . \%$ on the tensile strength and tensile modulus of bio-epoxy polymer composites is shown in Figures 6 and 7, respectively. For both Figures 6 and 7 , the lower case letters $a, b, c, \ldots$ are the results from statistical ranking using Tukey's method at 95\% confidence level. The inclusion of eggshell and limestone in the bio-epoxy matrix decreased the tensile strength with an increase in filler loading up to $20 \mathrm{wt} \%$. In contrast, the tensile modulus tended to increase with filler loadings. The unfilled bio-epoxy had a tensile strength of $60 \mathrm{MPa}$, which is similar to the manufacturers' data sheet $(62 \mathrm{MPa})$. The untreated fillers with composite loadings of 5, 10, and $20 \mathrm{wt}$. $\%$ reduced in tensile strength by approximately $15 \%, 25 \%$, and $31 \%$, respectively, for eggshells, whereas the composites with limestone fillers decreased by $16 \%$, $28 \%$, and $32 \%$, respectively, compared to the unfilled bio-epoxy. Interestingly, eggshell composites had slightly better tensile strengths than those of limestone composites. This may be due to the presence of inherent hydroxyl, carboxyl, and amino functional groups contained in the organic eggshell membranes, which act to promote hydrogen bonding with the epoxy matrix [27]. This suggests removal of the organic membranes may not be required because they promote adhesion to the epoxy. Depending on the end use and whether or not the composite is loaded in tension, eggshell or limestone loadings of 5, 10, and $20 \mathrm{wt}$ \% may be acceptable. For instance, assuming the application required a tensile strength of $30 \mathrm{MPa}$, then all filler loadings would be acceptable such that a higher strength would not be required. The benefit of these composites is to repurpose a waste material while reducing the overall cost of the polymer. However, filler loadings below 5 wt.\% would be a better choice. The results showed loadings above $5 \mathrm{wt}$ \% further reduced the composite tensile strength below that of the bio-epoxy matrix. Although the particles were thoroughly mixed into the resin during composite processing, particulate fillers added in greater amounts (e.g., 10 and $20 \mathrm{wt}$ \%) may tend to agglomerate due to electrostatic forces existing between the small particles [28]. Agglomeration suggests poor dispersion of fillers in the matrix. These agglomerates are sites of stress concentration, which aid in crack initiation and propagation to induce brittle failure [12,29]. The results are in agreement with a study that reported a decrease in tensile strengths with a increase in untreated eggshell loadings (particle size of $90 \mu \mathrm{m}$ ) in a polypropylene matrix. The authors believed the reductions were due to stress concentrations as a result of higher filler loadings (e.g., 20, 30 , and $40 \mathrm{wt} . \%$ ) [10]. In contrast, another study reported improved tensile strengths when smaller particle sizes $(0.2 \mu \mathrm{m})$ of eggshell fillers were added to a polyvinyl chloride matrix at $10 \mathrm{wt} . \%$ filler content [30]. The increase in the composite properties may be attributed to the smaller particle size fillers and processing technique [11,31]. 


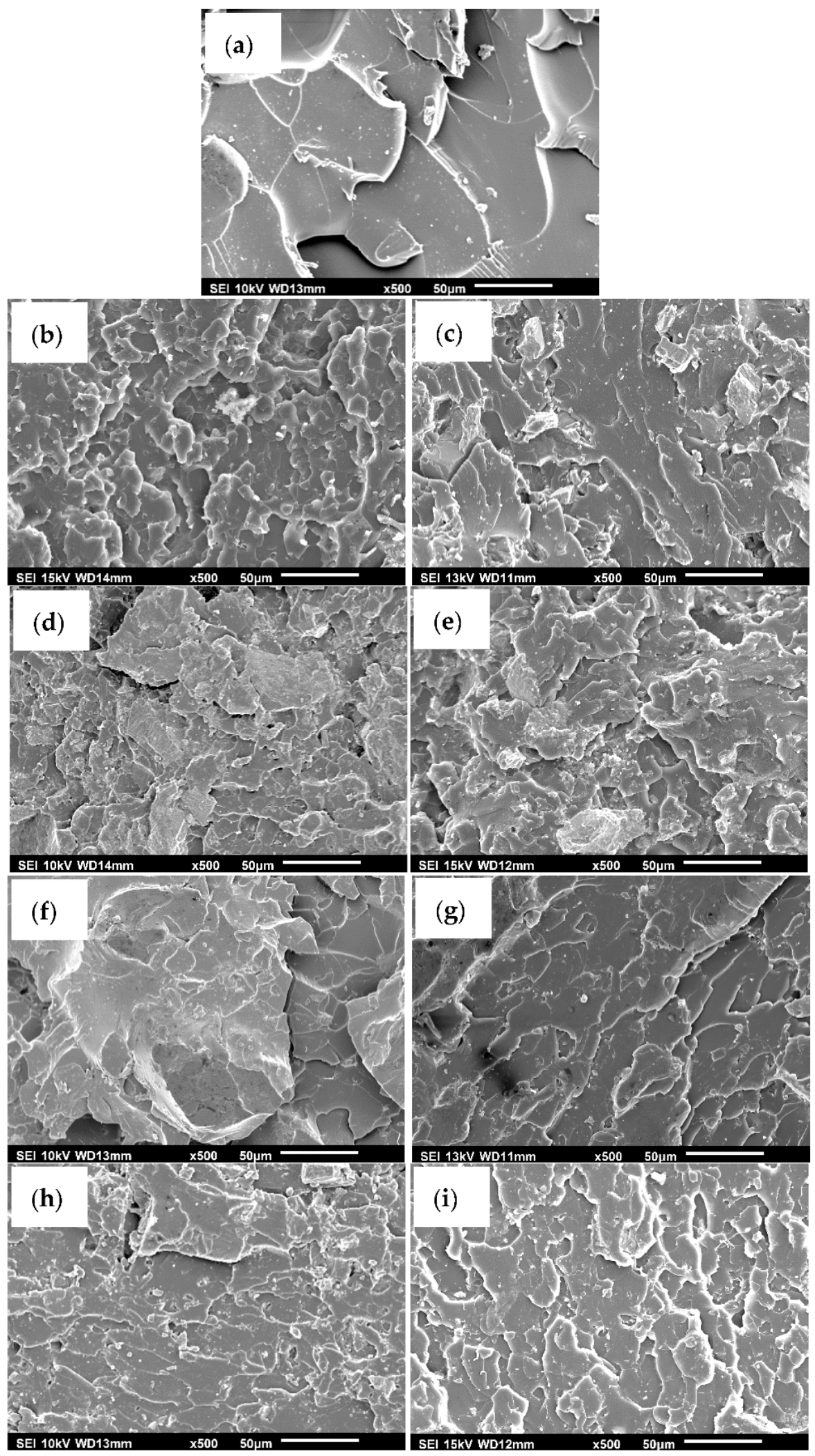

Figure 5. SEM micrographs of flexural fractured surfaces of (a) unfilled bio-epoxy, (b) 5 wt.\% ES, (c) 5 wt.\% ES/SA, (d) 20 wt.\% ES, (e) 20 wt.\% ES/SA, (f) 5 wt.\% LS, (g) 5 wt.\% LS/SA, (h) 20 wt.\% LS, and (i) 20 wt.\% LS/SA. 


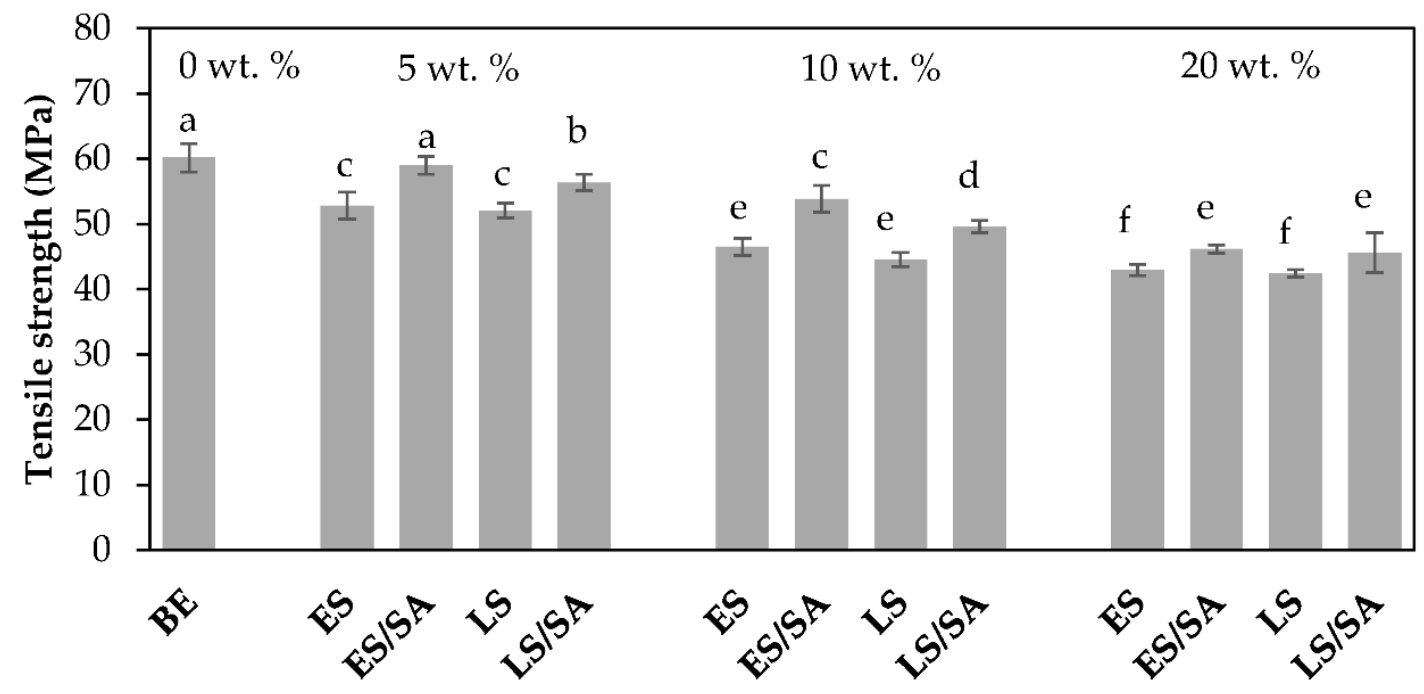

Figure 6. Tensile strength of unfilled bio-epoxy and bio-epoxy composites with loadings of 5-20 wt. $\%$, where a,b,c ... are the results from statistical ranking using Tukey's method at 95\% confidence level.

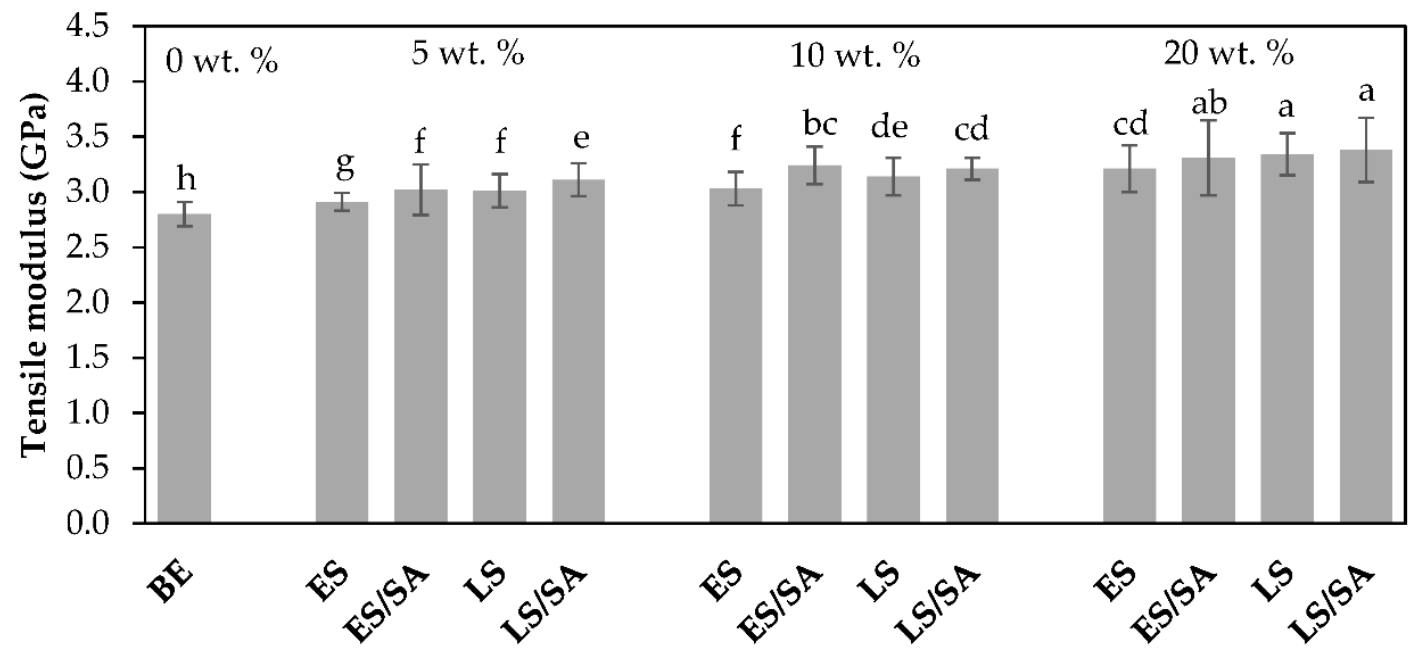

Figure 7. Tensile modulus of unfilled bio-epoxy (BE) and bio-epoxy composites with loadings of 5-20 wt.\%, where a,b,c ... are the results from statistical ranking using Tukey's method at 95\% confidence level.

In an effort to improve the tensile strengths and reduce agglomeration of $\mathrm{CaCO}_{3}$ particles, the effect of stearic acid treated fillers on the bio-epoxy matrix composites was evaluated. The stearic acid treated fillers with loadings of 5, 10, and $20 \mathrm{wt} . \%$ reduced tensile strengths by approximately $5 \%, 13 \%$, and $26 \%$, respectively, for eggshell fillers, and by $9 \%, 20 \%$, and $26 \%$, respectively, for limestone fillers compared to the unfilled bio-epoxy. However, the tensile strengths slightly improved by $12 \%, 16 \%$, and $7 \%$ for eggshells treated with stearic acid, and by $5 \%, 11 \%$, and $7 \%$, respectively, for limestone treated with stearic acid compared to the untreated filler composites. Despite the improvement in the tensile strengths of the stearic acid treated fillers, the composite strength values were not higher than those of the unfilled bio-epoxy matrix. The results suggest the stearic acid surface treatment had a minor effect for improving dispersion of fillers, reducing agglomeration of particles, and promoting a more effective stress transfer from matrix to filler [11]. In a similar work, polypropylene eggshell composites containing average particles of $90 \mu \mathrm{m}$ with stearic acid surface coatings of $6 \mathrm{wt} . \%$ showed an improvement in composite tensile strengths when $10 \mathrm{wt} . \%$ filler contents were added compared to the untreated eggshell fillers. The results also showed that higher filler loadings (e.g., 20, 30, and $40 \mathrm{wt} . \%$ ) tended to further reduce the tensile strengths for both types of fillers (untreated and treated) [10]. 
Typically, the tensile strength of a particle filled polymer decreases due to a reduce load bearing cross-section from the fillers and by the interaction of the polymer-filler [32]. Filler materials are not always added to polymers to improve the tensile strength but often to reduce the total cost of the more expensive polymer without greatly affecting its properties. A study showed a high-density polyethylene (HDPE) composite with filler size of 65 mesh (or $<212 \mu \mathrm{m}$ ) containing $20 \mathrm{wt} . \%$ stearic acid-coated eggshells had a moderate tensile strength improvement of about $25 \%$ compared to the untreated eggshells. In general, composites containing eggshells treated with stearic acid had better tensile strengths than the composites containing calcium carbonate treated with stearic acid. The authors attributed the results to better interfacial adhesion between the filler and the HDPE matrix for stearic acid-coated fillers [33]. In the current study, the trend was similar, such that the stearic acid treated filler composites had a slightly higher tensile strength than the untreated filler composites. This may be attributed to the adhesion between the bio-epoxy matrix and filler particles. Statistical analysis and ranking of the results for tensile strength shown in alphabetical order in the columns of Figure 6 indicated that the bio-epoxy and the composite with $5 \mathrm{wt} . \% \mathrm{ES} / \mathrm{SA}$ had the highest strength amongst all formulations. The weakest materials in terms of tensile strength were composites containing $20 \mathrm{wt} . \% \mathrm{ES}$ or LS according to the statistical analysis.

The unfilled bio-epoxy had a tensile modulus of $2.80 \mathrm{GPa}$, comparable to the manufacturers' data sheet (2.7-3.2 GPa). For the untreated fillers, with loadings of 5, 10, and $20 \mathrm{wt} . \%$, the tensile modulus was enhanced by $4 \%, 8 \%$, and $15 \%$, respectively, for eggshells and improved by $8 \%, 12 \%$, and $19 \%$, respectively, for limestone composites compared to the unfilled bio-epoxy. With the addition of a stiffer filler material such as eggshell or limestone, for which the modulus of their mineral $\mathrm{CaCO}_{3}$ has been reported to be $88 \mathrm{GPa}$ [34] compared to $2.80 \mathrm{GPa}$ for pure bio-epoxy, the composites tended to slightly increase in stiffness. The composite tensile modulus followed with an increase in filler loadings for both eggshell and limestone. Similarly, the tensile modulus improved by $8 \%, 16 \%$, and $18 \%$ for eggshells treated with stearic acid, and by $11 \%, 15 \%$, and $21 \%$, respectively, for limestone treated with stearic acid compared to the untreated filler composites. A related study observed an improvement in tensile modulus for polypropylene composites combined with either untreated eggshells or eggshells treated with stearic acid fillers, where the stearic acid treated filler composites showed the best improvements in tensile modulus [10]. Similar to stearic acid-coated eggshells, a study showed low-density polyethylene (LDPE) composites containing 5 to $25 \mathrm{wt} . \%$ of $63 \mu \mathrm{m}$ size eggshell powders treated with $\mathrm{NaOH}$ increased in tensile modulus with the increase in filler loading for both untreated and $\mathrm{NaOH}$ treated eggshell fillers compared to the pure LDPE matrix [35]. In a related work, polyethylene composites containing $5-40 \mathrm{wt} . \%$ of $25 \mu \mathrm{m}$ size filler particle loadings exhibited higher tensile modulus compared to pure polyethylene. The influence of eggshells treated with silane and titanate coatings marginally improved the modulus over the uncoated fillers [5]. According to the statistical analysis shown in alphabetical order in the columns of Figure 7, the bio-epoxy had the lowest modulus amongst all composites, which was significantly meaningful (95\% confidence level). By comparison, composites with $20 \mathrm{wt} . \%$ LS, ES/SA, and LS/SA resulted in the highest tensile modulus, which was statistically meaningful and higher than other formulations.

\subsection{Flexural Properties}

The flexural properties displayed a similar trend to the tensile results. The effect of untreated eggshells, untreated limestone, eggshell treated with stearic acid, and limestone treated with stearic acid filler loadings of 5, 10, and $20 \mathrm{wt} . \%$ on the flexural strength and flexural modulus properties of bio-epoxy polymer composites are shown in Figures 8 and 9, respectively. For both Figures 8 and 9, the lower case letters $a, b, c, \ldots$ are the results from statistical ranking using Tukey's method at $95 \%$ confidence level. The addition of eggshell and limestone to the bio-epoxy matrix tended to decrease the flexural strength and improve the flexural modulus. The bio-epoxy without fillers had the highest flexural 
strength of 95.7 MPa, comparable with the manufacturers' data sheet (92.7 MPa). The untreated eggshell and limestone filler types showed similar flexural behaviors. For instance, composites containing 5, 10, and $20 \mathrm{wt}$. \% of untreated fillers decreased by 10\%, $25 \%$, and $40 \%$, and by $11 \%, 24 \%$, and $38 \%$ for eggshell and limestone fillers, respectively, compared to the unfilled bio-epoxy. With a $5 \mathrm{wt} . \%$ filler content, a drop in strength of 10-11\% was observed compared to the unfilled bio-epoxy matrix, signifying larger filler contents are ineffective at improving the flexural strength. Similar to the tensile strength results, clustering of filler particles, which is more significant at higher loadings, may create stress concentration zones causing cracks to develop within the polymer matrix, thus inducing early failure [12,29]. The results are consistent with a previous study that reported an increase in flexural strength with low eggshell loadings (1 and 2 wt.\%) of particle sizes less than $10 \mathrm{~nm}(0.01 \mu \mathrm{m})$ in a polyester matrix, whereas at higher loadings (3 wt.\%) the strengths reduced [36]. In contrast, a similar study reported a slight improvement $(8-10 \%)$ in flexural strengths when 5 and $10 \mathrm{wt. \%}$ nano-eggshell (specific nanoparticle size was not mentioned) loadings were added to a Super Sap epoxy [25]. Although the eggshell treated with stearic acid and limestone treated with stearic acid filler composites fell slightly below the flexural strength of the unfilled bio-epoxy, the addition of these stearic acid-treated fillers presented a minor increase in flexural strength compared to that of the untreated filler composites. For example, as the eggshell treated with stearic acid filler loadings increased by 5,10 , and $20 \mathrm{wt} . \%$, the composite flexural strengths reduced by approximately $5 \%, 20 \%$, and $35 \%$, respectively, whereas the limestone-treated stearic acid fillers decreased the composite strengths by $6 \%, 20 \%$, and $37 \%$, respectively. The stearic acid-treated filler composites containing $5 \mathrm{wt}$.\% loadings presented a reduction of 5-6\% (compared to $10-11 \%$ for untreated fillers) in flexural strength. This moderate improvement suggests the stearic acid treatment reduced the surface energy of the $\mathrm{CaCO}_{3}$ filler particles, enhanced particle dispersion in the matrix, and promoted good interfacial interaction between the filler and matrix. A study also showed eggshells treated with stearic acid and added to HDPE composites containing $20 \mathrm{wt}$. $\%$ fillers $(<212 \mu \mathrm{m}$ particle size) had better flexural strength than the untreated eggshells. Analogous to the tensile strength results, the composites containing eggshell treated with stearic acid had enhanced flexural strengths compared to the composites with calcium carbonate-treated stearic acid. The authors believed the improvement in flexural strengths may have been due to the increase in the crystallinity of treated HDPE/eggshell composites compared to the untreated ones [33]. In the current study, the XRD results shown in Figure 1 for stearic acid coated fillers do not provide conclusive evidence for a change of crystallinity in the diffraction peak intensities. Statistical analysis for flexural strength indicated that the difference between the bio-epoxy and the composites was significant with higher strength for the bio-epoxy. At each loading level, composites containing ES/SA or LS/SA resulted in superior strength compared to those with ES or LS. Composites with higher percentages of fillers had the lowest flexural strength amongst all, as shown by the statistical analysis at the $95 \%$ confidence level.

The flexural modulus of both untreated and stearic acid-treated filler composites improved with the increase in filler loadings compared to the unfilled bio-epoxy, as shown in Figure 9. The flexural modulus of the unfilled bio-epoxy was $2.5 \mathrm{GPa}$, compared to 2.8 GPa from the manufacturers' data sheet. As the untreated filler loadings increased from 5 to 10 and $20 \mathrm{wt} \%$, the eggshell composite flexural modulus increased by $8 \%, 15 \%$, and $15 \%$, respectively, and the limestone composites improved by $11 \%, 17 \%$, and 19\%, respectively. At $20 \mathrm{wt}$ \% filler loadings for both eggshell and limestone composites, the flexural modulus increased by 15 and 19\%, respectively, compared to the unfilled bio-epoxy. This improvement may be attributed to the higher stiffness of the limestone filler material. The increase in flexural modulus with eggshell fillers agrees with results obtained by other studies which saw an improvement in a Super Sap epoxy composite with up to $4 \mathrm{wt}$ \% loading [25] and green polyethylene with maximum loadings of $40 \mathrm{wt} \%$ [5]. In the same manner, another study reported an increase in flexural modulus of a GreenPoxy composite with inclusions of ground seashell (mainly composed of calcium carbonate) 
fillers up to $30 \mathrm{wt} . \%$ loadings [37]. Coating the eggshell and limestone fillers with stearic acid also increased the flexural modulus of the composites slightly above the untreated filler composites. For instance, as the stearic treated filler loadings increased from 5 to 10 and $20 \mathrm{wt} . \%$, the flexural modulus of the eggshell composites improved by $17 \%, 19 \%$, and $21 \%$, respectively, and the limestone composites increased by $16 \%, 18 \%$, and $20 \%$, respectively. At $20 \mathrm{wt} . \%$ filler loadings, the flexural modulus for both eggshells treated with stearic acid and limestone treated with stearic acid improved by $20 \%$ and $21 \%$ (15\% and $19 \%$ for untreated fillers), respectively, compared to the unfilled bio-epoxy. In addition to the rigid $\mathrm{CaCO}_{3}$ particulates, the stearic acid acts to improve the interface between the fillers and the bio-epoxy matrix. A study on stearic acid-coated calcium carbonate particulate composites with sizes in the range of $0.18-0.25 \mu \mathrm{m}$ were observed to improve in flexural modulus by as much as $30 \%$ at a $15 \mathrm{wt} . \%$ loading compared to the neat polypropylene matrix [38]. According to the statistical analysis, the flexural modulus of the bio-epoxy was significantly lower than the other composites followed by ES- and LS-filled composites at $5 \mathrm{wt} . \%$ loading. At higher filler loadings, the modulus appeared to level off, as shown in Figure 9 .

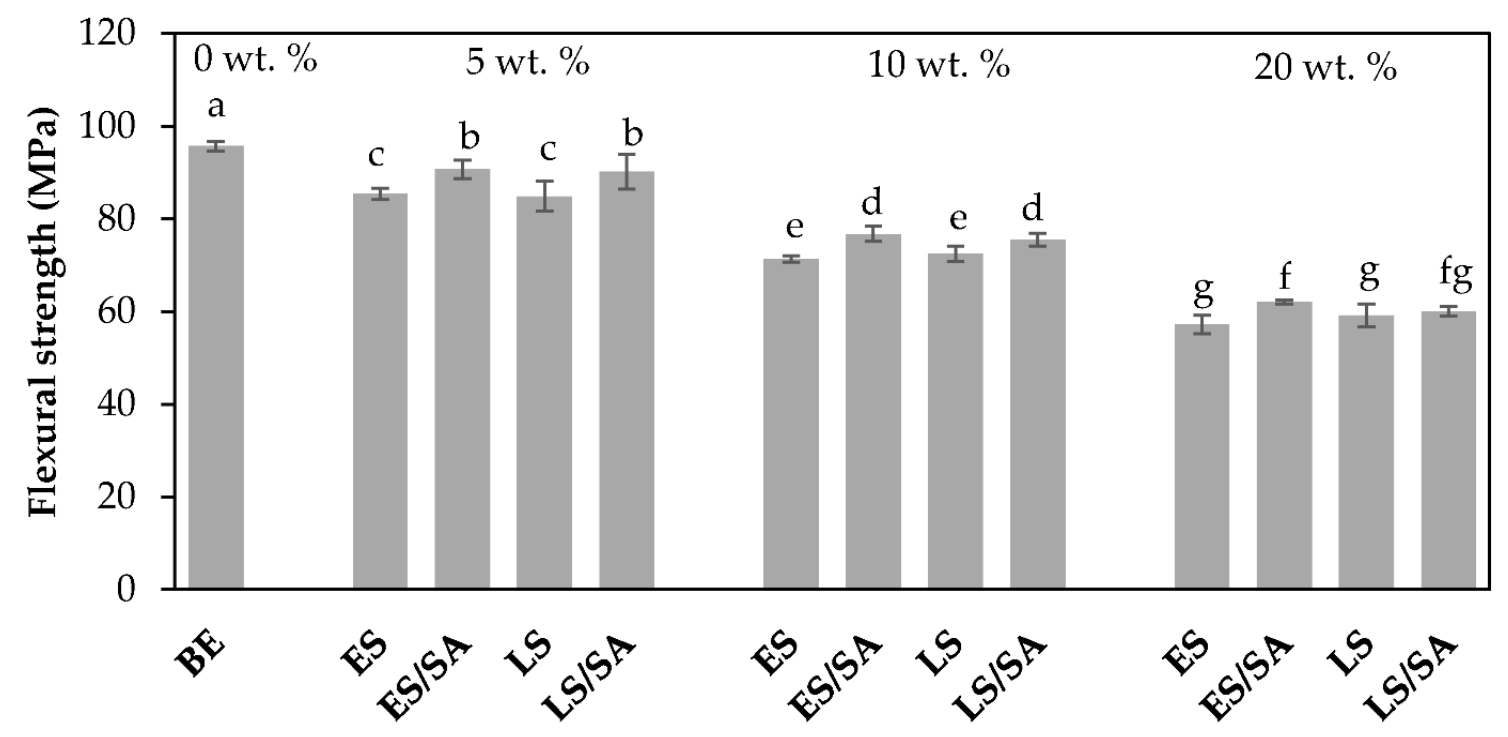

Figure 8. Flexural strength of unfilled bio-epoxy and bio-epoxy composites with loadings of 5-20 wt.\%, where a,b,c ... are the results from statistical ranking using Tukey's method at $95 \%$ confidence level.

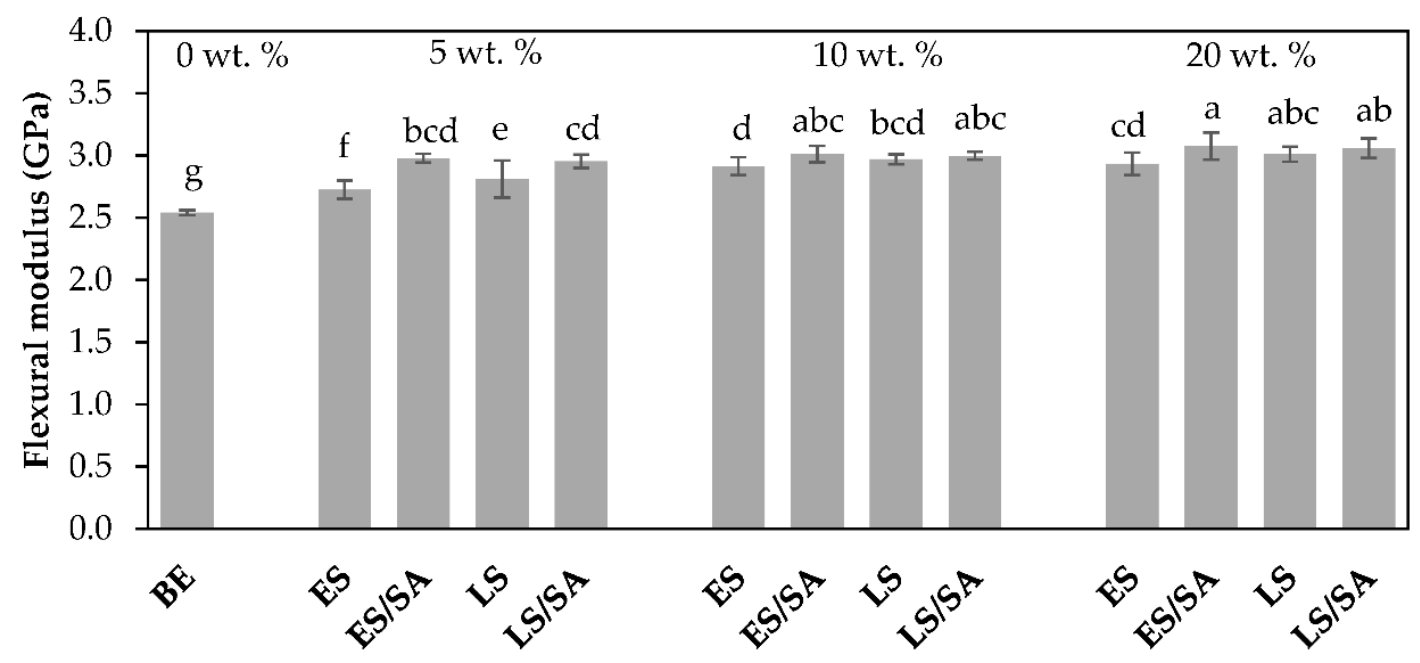

Figure 9. Flexural modulus of unfilled bio-epoxy and bio-epoxy composites with loadings of 5-20 wt.\%, where a,b,c ... are the results from statistical ranking using Tukey's method at 95\% confidence level. 


\subsection{Charpy Impact Energy Properties}

The Charpy test was conducted at room temperature $\left(23^{\circ} \mathrm{C}\right)$ and $-40{ }^{\circ} \mathrm{C}$ on bio-epoxy composites containing untreated eggshell, untreated limestone, eggshell treated with stearic acid, and limestone treated with stearic acid fillers in amounts of 5, 10, and $20 \mathrm{wt} . \%$. The results are shown in Figures 10 and 11, respectively. For both Figures 10 and 11, the lower case letters $a, b, c, \ldots$ are the results from statistical ranking using Tukey's method at $95 \%$ confidence level. As shown in Figure 10, at $23^{\circ} \mathrm{C}$, the unfilled bio-epoxy had an impact energy of $8.21 \mathrm{~kJ} / \mathrm{m}^{2}$. The energy absorbed by the composites decreased with an increase in filler content for both untreated filler types at $23^{\circ} \mathrm{C}$ and $-40{ }^{\circ} \mathrm{C}$. As the filler loadings increased from 5 to 10 and $20 \mathrm{wt} . \%$, the Charpy impact energy for composites containing eggshells decreased by $14 \%, 34 \%$, and $44 \%$, respectively, and the limestone fillers reduced the composite impact toughness by $9 \%, 31 \%$, and $41 \%$, respectively, compared to the unfilled bio-epoxy. In a similar manner, composites encompassing stearic acid treated fillers also exhibited a decrease in Charpy impact toughness with an increase in filler loadings. For example, as the filler loadings increased from 5 to 10 and $20 \mathrm{wt} . \%$, the Charpy impact toughness of the composites with eggshells treated with stearic acid decreased by $24 \%, 37 \%$, and $47 \%$, respectively, and that of composites with limestone treated with stearic acid fillers reduced by $20 \%, 36 \%$, and $43 \%$, respectively, compared to the unfilled bio-epoxy. Similar impact behaviours were reported for a GreenPoxy composite containing untreated seashell filler levels of 5, 10, 20, 30, and $40 \mathrm{wt} . \%$, where a remarkable decrease between $86-92 \%$ in toughness was reported compared to the polymer without fillers [37]. Although a study reported excellent particle size reduction and dispersion for polypropylene/eggshell composites, a decrease in impact strength with increasing eggshell content was witnessed. The authors suggested the particles in the polymer matrix intensify the chances for the development and propagation of micro-cracks throughout the matrix during the impact test, which results in the disruption of the polymer-filler interface [39]. The untreated eggshell and untreated limestone composites behaved slightly better than the stearic acid-treated filler composites. A similar study also found the impact strengths were not improved for both eggshells treated with stearic acid and calcium carbonate treated with stearic acid fillers, compared to the untreated composites [33].

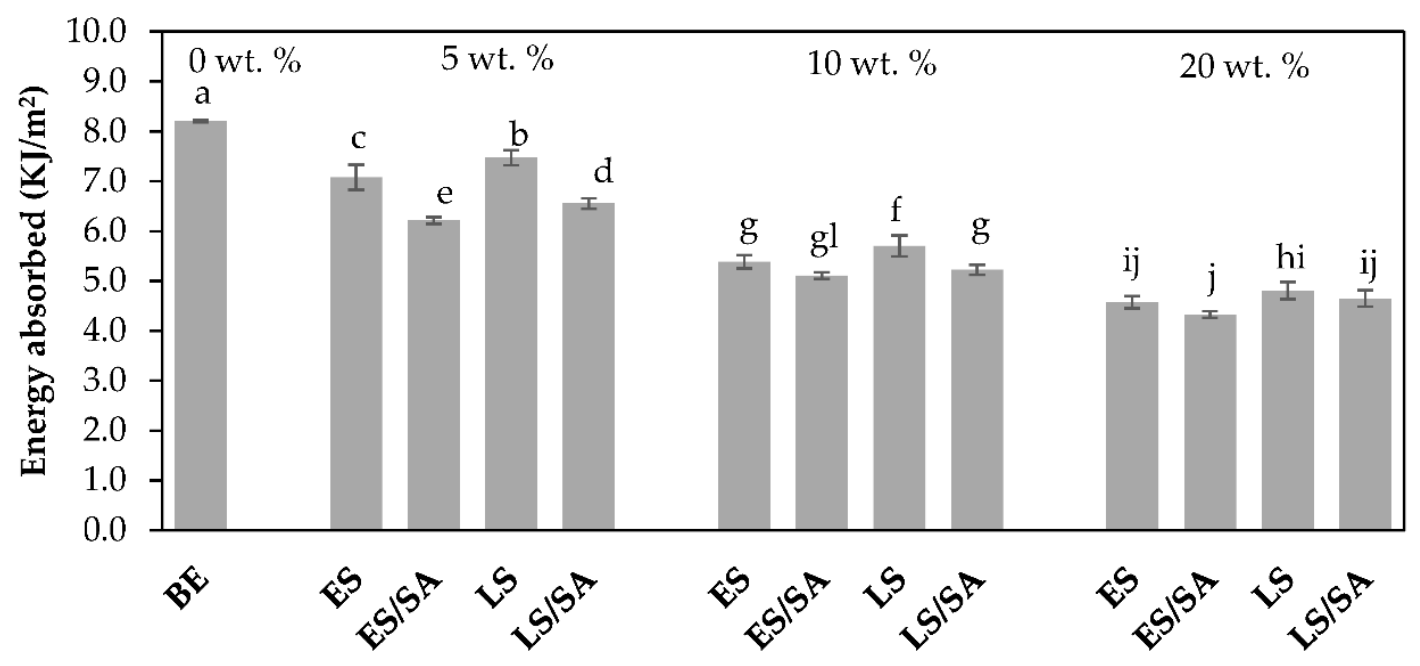

Figure 10. Effect of filler loadings on the Charpy impact energy absorbed by unfilled bio-epoxy and bio-epoxy composites with loadings of $5-20$ wt. $\%$ at $23^{\circ} \mathrm{C}$, where $\mathrm{a}, \mathrm{b}, \mathrm{c} \ldots$ are the results from statistical ranking using Tukey's method at $95 \%$ confidence level. 


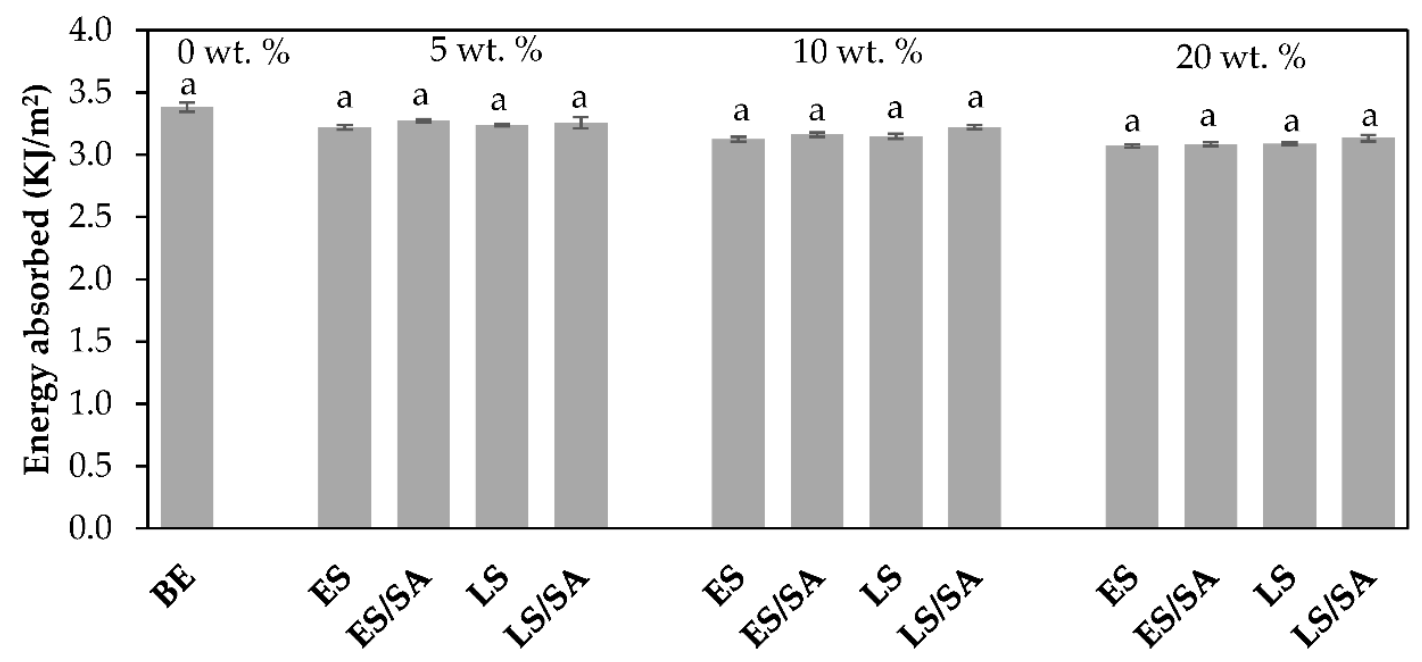

Figure 11. Effect of filler loadings on the Charpy impact energy absorbed by unfilled bio-epoxy and bio-epoxy composites with loadings of $5-20 \mathrm{wt} . \%$ at $-40{ }^{\circ} \mathrm{C}$, where a,b,c ... are the results from statistical ranking using Tukey's method at $95 \%$ confidence level.

The impact toughness values decreased remarkably when tested at $-40{ }^{\circ} \mathrm{C}$, as shown in Figure 11. For instance, the unfilled bio-epoxy had an impact energy of $3.38 \mathrm{~kJ} / \mathrm{m}^{2}$, a $58 \%$ decrease from its room temperature value. This suggests the bio-epoxy has an increasingly brittle behavior and is not able to absorb energy before fracture at relatively cold temperatures. With the addition of 5, 10, and $20 \mathrm{wt}$.\% filler loadings, the Charpy impact toughness of the composites did not improve at all filler levels and ranged in values of $3.07-3.24 \mathrm{~kJ} / \mathrm{m}^{2}$ for untreated eggshell and untreated limestone filler, and $3.09-3.27 \mathrm{~kJ} / \mathrm{m}^{2}$ for stearic acid-treated fillers. For example, the Charpy impact energy of the untreated eggshell composites decreased by $5 \%, 7 \%$, and $9 \%$, respectively, and that of the untreated limestone composites reduced by $4 \%, 7 \%$, and $9 \%$, respectively. In a similar manner, both stearic acid-treated fillers also did not positively affect the Charpy impact toughness at any of the filler loadings. For instance, the impact energy in the eggshell treated with stearic acid composites decreased by $3 \%, 7 \%$, and $9 \%$, respectively, and the energy in limestone treated with stearic acid composites reduced by $4 \%, 5 \%$, and $7 \%$, respectively. These drops in impact energy agree with a previous study which reported a decrease in impact fracture toughness of an epoxy composite evaluated at a low temperature of $-20^{\circ} \mathrm{C}$ [40]. According to the DSC results, the $\mathrm{T}_{\mathrm{g}}$ of the unfilled bio-epoxy was $56.3^{\circ} \mathrm{C}$ (Table 2 ); $-40{ }^{\circ} \mathrm{C}$ is well below this value, which suggests the bio-epoxy became less pliable, harder, and more brittle. The results highlight these bio-epoxy composites should not be used in cold weather if the application will be exposed to impact load. However, room temperature applications are more feasible at low filler loadings because the impact energy only decreased by $9-14 \%$ for $5 \mathrm{wt} . \%$ contents. In terms of statistical analysis, the difference in impact energy (at $23^{\circ} \mathrm{C}$ ) between composites was significant (in most cases) with lower values for the composites consisting of higher amounts of filler. However, no statistical difference was observed at $-40^{\circ} \mathrm{C}$ between the control and all composite formulations, as shown in Figures 10 and 11.

Table 2. The $\mathrm{T}_{\mathrm{g}}$-onset, $\mathrm{T}_{\mathrm{g}}$-midpoint and $\mathrm{T}_{\mathrm{g}}$-end temperature for pure bio-epoxy and composites with $5 \mathrm{wt}$ \% fillers.

\begin{tabular}{cccc}
\hline $\begin{array}{c}\text { Composite } \\
\text { Formulation }\end{array}$ & $\begin{array}{c}\mathbf{T}_{\mathbf{g}} \text {-Onset } \\
\text { Temperature }\left({ }^{\circ} \mathbf{C}\right)\end{array}$ & $\begin{array}{c}\mathbf{T}_{\mathbf{g}} \text {-Midpoint } \\
\text { Temperature }\left({ }^{\circ} \mathbf{C}\right)\end{array}$ & $\begin{array}{c}\mathbf{T}_{\mathbf{g}} \text {-End } \\
\text { Temperature }\left({ }^{\circ} \mathbf{C}\right)\end{array}$ \\
\hline BE & 54.1 & 56.3 & 58.4 \\
5 wt. $\%$ ES & 55.6 & 57.9 & 60.2 \\
5 wt. $\%$ ES/SA & 54.9 & 56.7 & 58.5 \\
5 wt. $\%$ LS & 55.1 & 56.4 & 57.7 \\
5 wt. $\%$ LS/SA & 54.8 & 56.4 & 58.0 \\
\hline
\end{tabular}




\subsection{Differential Scanning Calorimetry (DSC)}

DSC was used to evaluate the glass transition temperature $\left(T_{g}\right)$ of the pure bio-epoxy and to determine if any deviations occurred due to the addition of the fillers. In this study, unfilled bio-epoxy resin and $5 \mathrm{wt} . \%$ filled composites (ES, LS, ES treated with SA, and LS treated with $\mathrm{SA}$ ) were evaluated for their $\mathrm{T}_{\mathrm{g}}$ because they presented better tensile strength, flexural strength, and Charpy impact energy (most promising material) than those with increased filler loadings. The $\mathrm{T}_{\mathrm{g}}$-onset, $\mathrm{T}_{\mathrm{g}}$-midpoint, and $\mathrm{T}_{\mathrm{g}}$-end point temperatures of the unfilled bio-epoxy resin and $5 \mathrm{wt} . \%$ composite formulations are given in Table 2 . The $\mathrm{T}_{\mathrm{g}}$-midpoint temperatures were calculated as an average of the onset and end transition temperatures obtained from the heat flow curves given in Figure 12. The results showed the $\mathrm{T}_{\mathrm{g}}$-midpoint obtained for the unfilled bio-epoxy was $56.3^{\circ} \mathrm{C}$, which is within the value reported in the manufacturers' data sheet $\left(54.0^{\circ} \mathrm{C}\right)$. The inclusion of a low concentration of untreated eggshell and limestone fillers into the bio-epoxy matrix had a minor effect on the polymer network, which slightly increased the $\mathrm{T}_{\mathrm{g}}$-midpoint compared to unfilled bio-epoxy. For example, the inclusion of $5 \mathrm{wt} . \%$ untreated eggshell filler increased the $\mathrm{T}_{\mathrm{g}}$-midpoint by $1.6^{\circ} \mathrm{C}$, whereas the $5 \mathrm{wt} . \%$ limestone composite, $5 \mathrm{wt} . \%$ eggshell treated with stearic acid composite, and the $5 \mathrm{wt} . \%$ limestone treated with stearic acid composite saw no significant change in the $\mathrm{T}_{\mathrm{g}}$-midpoint in comparison to the unfilled bio-epoxy resin. A study reported similar observations in which there were no significant changes in the glass transition temperatures for synthetic epoxy composites containing 2, 4, and $6 \mathrm{wt}$. $\%$ calcium carbonate fillers [41]. The results suggest that at $5 \mathrm{wt} . \%$ there may be not enough filler material distributed within the bio-epoxy matrix to make a substantial change in the $\mathrm{T}_{\mathrm{g}}$-midpoint.

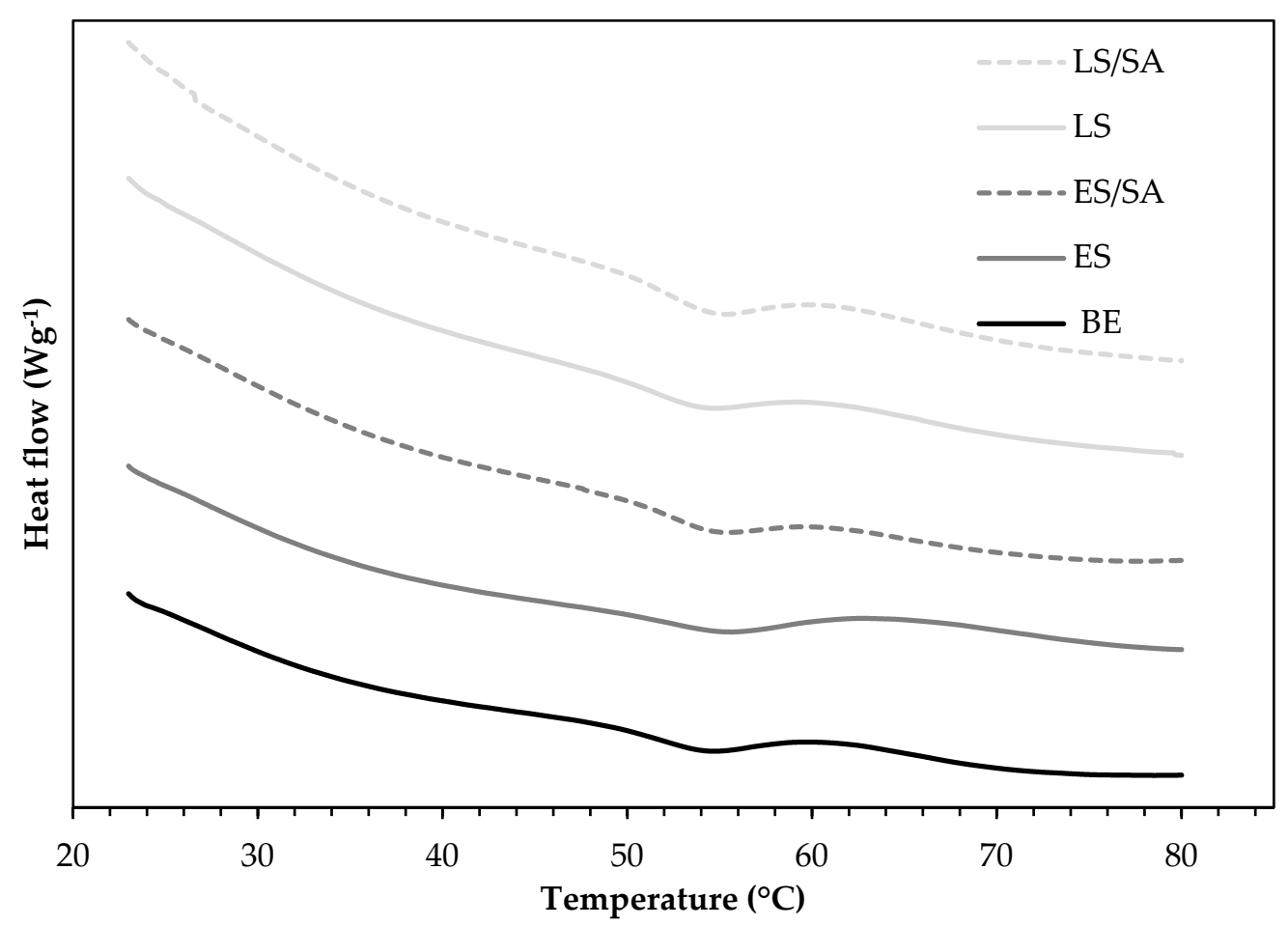

Figure 12. DSC thermographs showing the effect of 5 wt.\% ES, LS, and SA-treated ES and LS fillers on the $\mathrm{T}_{\mathrm{g}}$ of bioepoxy composites.

The addition of $\mathrm{CaCO}_{3}$ particulate fillers to the bio-epoxy polymer negatively influenced the tensile strength, flexural strength, and impact strength, but had a positive effect on the tensile and flexural modulus. The reduction was generally due to the presence of geometric discontinuities of the filler particles in an otherwise continuous matrix, which acted as stress concentrations that led to the composite failure. In contrast, the composite 
tensile and flexural stiffness tended to increase due to the rigid particles being stiffer than the matrix. Future work will entail lower filler contents ( $<5 \mathrm{wt}$. $\%$ fillers), smaller particle sizes, and moisture and/or water sorption experiments.

\section{Conclusions}

This study evaluated the mechanical properties of eggshell and limestone bio-epoxy composites with different filler loadings for potential filler applications in bio-epoxy resin. The results showed that although the fillers improved tensile and flexural moduli, the disadvantage of adding particulate fillers to polymers is generally a decrease in tensile strength, flexural strength, and Charpy impact strength. The composites containing stearic acid-coated fillers did not have better mechanical properties than the unfilled bio-epoxy, possibly due to the low level of surface coating. The Charpy impact tests were conducted at $23{ }^{\circ} \mathrm{C}$ and $-40{ }^{\circ} \mathrm{C}$, where the results revealed that cold weather applications in which impact toughness is required are not recommended for this bio-epoxy composite material. Based on the observations in this study, future work can entail lower than $5 \mathrm{wt}$ \% filler contents, because it was shown that at 10 and $20 \mathrm{wt} . \%$ loadings, the tensile strength, flexural strength, and Charpy impact degraded quickly. It would also be beneficial to verify if trace elements found in eggshells have an effect on the polymer composite properties.

Author Contributions: Conceptualization, D.E.C. and S.O.; methodology, D.E.C.; formal analysis, S.O. and M.S.; investigation, S.O.; resources, D.E.C.; data curation, S.O. and D.E.C.; writing-original draft preparation, D.E.C.; writing-review and editing, D.E.C.; supervision, D.E.C. and M.S.; project administration and funding acquisition, D.E.C. All authors have read and agreed to the published version of the manuscript.

Funding: This research was funded by Natural Sciences and Engineering Research Council of Canada (NSERC), Discovery Grant (RGPIN-2020-06701) and the University of Saskatchewan Undergraduate Student Research Assistantship. The APC was funded by MDPI.

Institutional Review Board Statement: Not applicable.

Informed Consent Statement: Not applicable.

Data Availability Statement: The data presented in this study are available on request from the corresponding author. The data are not publicly available due to the raw/processed data required to reproduce these findings cannot be shared at this time as the data also forms part of an ongoing study.

Conflicts of Interest: The authors declare no conflict of interest. The funders had no role in the design of the study; in the collection, analyses, or interpretation of data; in the writing of the manuscript, or in the decision to publish the results.

\section{References}

1. Millet, H.; Vangheluwe, P.; Block, C.; Sevenster, A.; Garcia, L.; Antonopoulos, R. The Nature of Plastics and Their Societal Usage. Issues Environ. Sci. Technol. 2018, 1-20. Available online: https://pubs.rsc.org/en/content/chapterhtml/2018/9781788013314-0 0001?isbn=978-1-78801-241-6 (accessed on 22 September 2021).

2. Kaw, A.K. Mechanics of Composite Materials, 2nd ed.; CRC Press: Boca Raton, FL, USA, 2006.

3. Baroncini, E.A.; Yadav, S.K.; Palmese, G.R.; Stanzione III, J.F. Recent advances in bio-based epoxy resins and bio-based epoxy curing agents. J. Appl. Polym. Sci. 2016, 133, 1-19. [CrossRef]

4. Pliya, P.; Cree, D. Limestone derived eggshell powder as a replacement in Portland cement mortar. Constr. Build. Mater. 2015, 95, 1-9. [CrossRef]

5. Boronat, T.; Fombuena, V.; Garcia-Sanoguera, D.; Sanchez-Nacher, L.; Balart, R. Development of a biocomposite based on green polyethylene biopolymer and eggshell. Mater. Des. 2015, 68, 177-185. [CrossRef]

6. Intharapat, P.; Kongnoo, A.; Kateungngan, K. The potential of chicken eggshell waste as a bio-filler filled epoxidized nat-ural rubber (ENR) composite and its properties. J. Polym. Environ. 2013, 21, 245-258. [CrossRef]

7. Sonenklar, C. Famous for egg waste. Res. State News Penn State Univ. 1999, 1-2. Available online: https://news.psu.edu/story/14 0891/1999/09/01/research/famous-egg-waste (accessed on 22 September 2021).

8. Owuamanam, S.; Cree, D. Progress of Bio-Calcium Carbonate Waste Eggshell and Seashell Fillers in Polymer Composites: A Review. J. Compos. Sci. 2020, 4, 70. [CrossRef]

9. Shah, A.H.; Zhang, Y.; Xu, X.; Dayo, A.Q.; Li, X.; Wang, S.; Liu, W. Reinforcement of stearic acid treated egg shell parti-cles in epoxy thermosets: Structural, thermal, and mechanical characterization. Materials 2018, 11, 1872. [CrossRef] [PubMed] 
10. Ghabeer, T.; Dweiri, R.; Al-Khateeb, S. Thermal and mechanical characterization of polypropylene/eggshell biocomposites. J. Reinf. Plast. Compos. 2013, 32, 402-409. [CrossRef]

11. Cao, Z.; Daly, M.; Clémence, L.; Geever, L.M.; Major, I.; Higginbotham, C.L.; Devine, D.M. Chemical surface modifica-tion of calcium carbonate particles with stearic acid using different treating methods. Appl. Surf. Sci. 2016, 378, 320-329. [CrossRef]

12. Mohan, T.P.; Kanny, K. Thermal, mechanical and physical properties of nanoegg shell particle-filled epoxy nanocompo-sites. $J$. Compos. Mater. 2018, 52, 3989-4000. [CrossRef]

13. Mihajlović, S.; Sekulić, Z.; Daković, A.; Vučinić, D.; Jovanović, V.; Stojanović, J. Surface properties of natural calcite filler treated with stearic acid. Ceramics-Silikáty 2009, 53, 268-275.

14. Bittmann, B.; Haupert, F.; Schlarb, A.K. Ultrasonic dispersion of inorganic nanoparticles in epoxy resin. Ultrason. Sonochem. 2009, 16, 622-628. [CrossRef]

15. Chatterjee, A.; Islam, M.S. Fabrication and characterization of TiO2-epoxy nanocomposite. Mater. Sci. Eng. A 2008, 487, 574-585. [CrossRef]

16. Owuamanam, S. Fabrication and characterization of bio-epoxy eggshell composites. Master's Thesis, University of Saskatchewan, Saskatoon, SK, Canada, 2019.

17. ASTM International. Standard Test Method for Tensile Properties of Plastics; ASTM-D638-14; ASTM International: West Conshohocken, PA, USA, 2014.

18. ASTM International. Standard Test Methods for Flexural Properties of Unreinforced and Reinforced Plastics and Electrical Insulating Materials; ASTM D790-17; ASTM International: West Conshohocken, PA, USA, 2017.

19. ASTM International. Standard Test Method for Determining the Charpy Impact Resistance of Notched Specimens of Plastics; ASTM D6110-18; ASTM International: West Conshohocken, PA, USA, 2018.

20. Rothon, R. Particulate-Filled Polymer Composites, 2nd ed.; Rapra Technology Limited: Shropshire, UK, 2003.

21. ASTM International. Standard Test Method for Assignment of the Glass Transition Temperatures by Differential Scanning Calorimetry; ASTM E1356-08 (2014); ASTM International: West Conshohocken, PA, USA, 2008.

22. Cree, D.; Pliya, P. Effect of elevated temperature on eggshell, eggshell powder and eggshell powder mortars for masonry applications. J. Build. Eng. 2019, 26, 100852. [CrossRef]

23. Cree, D.; Rutter, A. Sustainable Bio-Inspired Limestone Eggshell Powder for Potential Industrialized Applications. ACS Sustain. Chem. Eng. 2015, 3, 941-949. [CrossRef]

24. Schultz, L.; Andersson, M.; Dalby, K.; Müter, D.; Okhrimenko, D.; Fordsmand, H.; Stipp, S. High surface area calcite. J. Cryst. Growth 2013, 371, 34-38. [CrossRef]

25. Tiimob, B.J.; Jeelani, S.; Rangari, V.K. Eggshell reinforced biocomposite-an advanced "green" alternative structural material. J. Appl. Polym. Sci. 2016, 133, 1-10. [CrossRef]

26. He, Y.; Fan, Y.; Luo, P.; Yang, Q. Synthesis of stearic acid modified ground calcium carbonate (SA-GCC) hybrid material and properties of SA-GCC/epoxy composites coating. Russ. J. Appl. Chem. 2015, 88, 962-969. [CrossRef]

27. Apalangya, V.; Rangari, V.; Tiimob, B.; Jeelani, S.; Samuel, T. Development of antimicrobial water filtration hybrid mate-rial from bio source calcium carbonate and silver nanoparticles. Appl. Surf. Sci. 2014, 295, 108-114. [CrossRef]

28. Lachiver, E.D.; Abatzoglou, N. Cartilier, LParticulate Systems. Pharm. Res. 2006, 23, 997-1007. [CrossRef]

29. Rahman, M.M.; Zainuddin, S.; Hosur, M.; Malone, J.; Salam, M.; Kumar, A.; Jeelani, S. Improvements in mechanical and thermomechanical properties of e-glass/epoxy composites using amino functionalized MWCNTs. Compos. Struct. 2012, 94, 2397-2406. [CrossRef]

30. Murugan, S.; Munusamy, Y.; Ismail, H. Effects of chicken eggshell filler size on the processing, mechanical and thermal properties of PVC matrix composite. Plast. Rubber Compos. 2016, 46, 42-51. [CrossRef]

31. Wu, D.; Wang, X.; Song, Y.; Jin, R. Nanocomposites of poly(vinyl chloride) and nanometric calcium carbonate particles: Effects of chlorinated polyethylene on mechanical properties, morphology, and rheology. J. Appl. Polym. Sci. 2004, 92, 2714-2723. [CrossRef]

32. Pukanszky, B.; Tüdös, F.; Jančař, J.; Kolařik, J. The possible mechanisms of polymer-filler interaction in polypropyl-ene-CaCO 3 composites. J. Mater. Sci. Lett. 1989, 8, 1040-1042. [CrossRef]

33. Dweiri, R. Processing and Characterization of Surface Treated Chicken Eggshell and Calcium Carbonate Particles Filled HighDensity Polyethylene Composites. Mater. Res. 2021, 24, 24. [CrossRef]

34. Bassam, F.; York, P.; Rowe, R.; Roberts, R. Young's modulus of powders used as pharmaceutical excipients. Int. J. Pharm. 1990, 64, 55-60. [CrossRef]

35. Shuhadah, S.; Supri, A.G. LDPE-isophthalic acid modified egg shell powder composites (LDPE/ESPI). J. Phys. Sci. 2009, 20, 87-98.

36. Hassan, T.A.; Rangari, V.K.; Jeelani, S. Mechanical and thermal properties of bio-based CaCO3/soybean-based hybrid unsaturated polyester nanocomposites. J. Appl. Polym. Sci. 2013, 130, 1442-1452. [CrossRef]

37. Fombuena, V.; Bernardi, L.; Fenollar, O.; Boronat, T.; Balart, R. Characterization of green composites from biobased epoxy matrices and bio-fillers derived from seashell wastes. Mater. Des. 2014, 57, 168-174. [CrossRef]

38. Hanim, H.; Zarina, R.; MY, A.F.; ZA, M.I.; Hassan, A. The effect of calcium carbonate nanofiller on the mechanical properties and crystallisation behaviour of polypropylene. Malays. Polym. J. 2008, 31, 38-49.

39. Iyer, K.A.; Torkelson, J.M. Green composites of polypropylene and eggshell: Effective biofiller size reduction and disper-sion by single-step processing with solid-state shear pulverization. Compos. Sci. Technol. 2014, 102, 152-160. [CrossRef] 
40. Khan, S.U.; Iqbal, K.; Munir, A.; Kim, J.K. Quasi-static and impact fracture behaviors of CFRPs with nanoclay-filled epoxy matrix. Compos. Part A Appl. Sci. Manuf. 2011, 42, 253-264. [CrossRef]

41. Jin, F.L.; Park, S.J. Thermal stability of trifunctional epoxy resins modified with nanosized calcium carbonate. Bull. Korean Chem. Soc. 2009, 30, 334-338. 